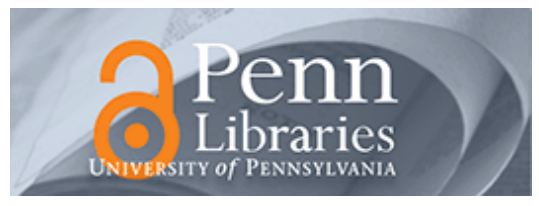

University of Pennsylvania

ScholarlyCommons

Marketing Papers

Wharton Faculty Research

$1-10-2015$

\title{
Misrepresentation of Credence Goods and Channel Design
}

Dinah Cohen-Vernik

Pinar Yildirim

University of Pennsylvania

Vikas Mittal

Follow this and additional works at: https://repository.upenn.edu/marketing_papers

Part of the Advertising and Promotion Management Commons, Business Administration, Management, and Operations Commons, Business Analytics Commons, Business and Corporate Communications Commons, Management Sciences and Quantitative Methods Commons, Marketing Commons, and the Operations and Supply Chain Management Commons

\section{Recommended Citation}

Cohen-Vernik, D., Yildirim, P., \& Mittal, V. (2015). Misrepresentation of Credence Goods and Channel Design. http://dx.doi.org/10.2139/ssrn.2552807

This is an unpublished manuscript.

This paper is posted at ScholarlyCommons. https://repository.upenn.edu/marketing_papers/338

For more information, please contact repository@pobox.upenn.edu. 


\title{
Misrepresentation of Credence Goods and Channel Design
}

\begin{abstract}
Credence goods are often delivered to consumers via a vertical channel where the true quality of the good is determined by a manufacturer (an upstream channel member), while consumers' quality perceptions are driven by the observable signals of quality sent by a retailer (a downstream channel member). We study product misrepresentation in a vertical channel with asymmetric information about true product quality and focus on conditions that incentivize downstream channel members to misrepresent product quality to consumers. We develop a model with credulous consumers who rely on seller signals of quality to determine their expected utility from consumption of goods. The model shows that product misrepresentation rises as an equilibrium outcome due to actions of both the manufacturer and the retailer. We suggest that channel design can be a mechanism mitigating the level of misrepresentation. Specifically, adding more retailers in a channel can reduce the extent of misconduct and can increase the profits of the channel members.
\end{abstract}

Keywords

B2B Marketing, misrepresentation, quality, product delivery, channel design

Disciplines

Advertising and Promotion Management | Business | Business Administration, Management, and Operations | Business Analytics | Business and Corporate Communications | Management Sciences and Quantitative Methods | Marketing | Operations and Supply Chain Management

\section{Comments}

This is an unpublished manuscript. 


\title{
Misrepresentation of Credence Goods and Channel Design
}

\author{
Dinah Cohen-Vernik ${ }^{*}$ Pinar Yildirim $†$ Vikas Mittal ${ }^{\ddagger}$
}

January 10, 2015

\begin{abstract}
Credence goods are often delivered to consumers via a vertical channel where the true quality of the good is determined by a manufacturer (an upstream channel member), while consumers' quality perceptions are driven by the observable signals of quality sent by a retailer (a downstream channel member). We study product misrepresentation in a vertical channel with asymmetric information about true product quality and focus on conditions that incentivize downstream channel members to misrepresent product quality to consumers. We develop a model with credulous consumers who rely on seller signals of quality to determine their expected utility from consumption of goods. The model shows that product misrepresentation rises as an equilibrium outcome due to actions of both the manufacturer and the retailer. We suggest that channel design can be a mechanism mitigating the level of misrepresentation. Specifically, adding more retailers in a channel can reduce the extent of misconduct and can increase the profits of the channel members.
\end{abstract}

Keywords: B2B Marketing, Misrepresentation, Quality, Product Delivery, Channel Design

${ }^{*}$ Cohen-Vernik is Assistant Professor of Marketing at the Jones School of Business, Rice University. Address: Rice University, McNair Hall, MS 531 Houston TX 77005. E-mail: cohenvernik@rice.edu.

${ }^{\dagger}$ Yildirim is Assistant Professor of Marketing at the Wharton School of the University of Pennsylvania. Address: Marketing Department, The Wharton School, Huntsman Hall Philadelphia PA 19104. E-mail: pyild@wharton.upenn.edu, phone: 215 746-2369.

${ }^{\ddagger}$ Mittal is J. Hugh Liedtke Professor of Marketing at the Jones School of Business, Rice University. Address: Rice University, McNair Hall, MS 531 Houston TX 77005. E-mail: vmittal@rice.edu.

${ }^{\S}$ Authors thank Christophe Van den Bulte and Amit Pazgal for their valuable input on the paper. 


\section{Introduction}

When buying a complex financial investment product (Inderst and Ottaviani, 2012a; Brown and Minor, 2012), deciding whether to undergo a surgery, or approving a mechanic's choice of an auto part for replacement (Wolinsky, 1993; Emons, 1997), consumers usually lack the necessary expertise to fully assess the quality of the product or service they are receiving. Such goods for which consumers cannot assess the value of the attributes with certainty are referred to as "credence goods" (Darby and Karni, 1973; Wolinsky, 1993). Credence goods differ from other types of goods in two ways. First, unlike experience goods, the true quality of a credence good may remain unknown to consumers even after purchase and consumption. For instance, a patient is unlikely to assess the true quality of a surgery she underwent, even after the surgery. Second, during the process of purchasing a credence good, consumers may rely on observable signals and advice provided by sellers due to their inability to assess product quality on their own. Sellers (i.e., retailers) typically have the knowledge and expertise about the products they offer and can better judge the true quality of a product relative to the consumer. For credence goods, therefore, retailers act not only as a point of sale, but also as the information intermediary between a manufacturer and a consumer. As an information intermediary, the retailer, in addition to providing the product or service itself, also provides the information signal regarding the product's quality. Thus, there exists an information asymmetry between the seller and consumers. Crucially, the information asymmetry may result in a moral hazard problem (Dulleck and Kerschbamer, 2006): An opportunistic seller may present a low-quality product to consumers as a high-quality product to increase consumer's willingness to pay, or, may undersell a high-quality product to lower consumers' expectations about product quality.

Examples of misrepresentation abound. In retail, gourmet food products and healthcare products may sometimes be sold with deceptive labels ${ }^{1}$ (Martinez, 2009). Body care products that are not truly organic, for instance, are misrepresented as "organic" (The Gourmet Retailer, 2012). The National Health Care Anti-Fraud Association (NHCAA) estimates "tens of billions of dollars each year are lost" due to health care providers selling unnecessary procedures (NHCAA, 2014). When buying home-remodeling products such as windows and doors, consumers are frequently warned

\footnotetext{
${ }^{1}$ For example, in 2006-7, over 3.2 million liters of olive oil were sold in Italy via misrepresentation that it was produced in Italy (versus packaged in Italy) and that it was pure extra virgin (versus a blend).
} 
to beware of companies misrepresenting low-quality products as high-end and reliable ones. ${ }^{2}$ In a similar vein, one contributing factor to the financial crisis in 2008 was misrepresentation of investment quality and the risk associated with financial products by investment advisors (Inderst and Ottaviani, 2012a).

Although misrepresentation affects manufacturers, retailers, and consumers at large, the conditions which give rise to it are grossly understudied in marketing. This paper addresses the issue of misrepresentation of credence goods in a vertical distribution channel, focusing on several important questions: First, what are the conditions that promote misrepresentation behavior among partners in a vertical channel? Specifically, does misrepresentation always arise due to the fault of one party, or is it a joint outcome emanating from a double moral hazard present in the channel? Second, how does the the manufacturer's choice of channel design affect the retailer's incentives for misrepresentation of the product's true quality? Specifically, are there any incentives for a manufacturer to choose an exclusive versus non-exclusive distribution channel to mitigate moral hazard? Third, and finally, how does the attribution of blame for quality problems to retailer influence the retailer's incentives to misrepresent product quality?

We address these questions by developing a stylized model of a vertical channel where the manufacturer sells its product via one or more retailers. The manufacturer can produce either a high or a low-quality product, and the retailers examine it in order to form their beliefs about product quality. Depending on the outcome of this examination and the wholesale prices set by the manufacturer, the retailers then decide whether or not to misrepresent product quality. Consumers make their purchase decisions based on the product quality signaled by the retailers and the retail prices. Following the tradition of papers analyzing credence goods (Kartik et al., 2007), the consumers in our model recognize the incentives of the sellers to misrepresent products; however, since consumers are unable to detect if a seller is truthful or not, they act credulously. If the product fails, consumers punish their source of quality perceptions, the retailer.

Our investigation provides several counter-intuitive, but theoretically relevant insights. First, instances of misrepresentation arise as a joint outcome of the decisions made by the retailers and manufacturers. Although retailers have full control on influencing consumer perceptions of quality, the manufacturer may also benefit when retailers misrepresents the quality of his product. As a re-

\footnotetext{
${ }^{2}$ See http : //web.aces.uiuc.edu/vista/pdf_pubs/RPRFRAUD.PDF, accessed on 4-1-2014.
} 
sult, the manufacturer may make quality and pricing choices to encourage misrepresentation by the retailer. Second, many manufacturers believe that vertically integrating retailers is the only strategy available to reduce misrepresentation (Minder, 2014). Our model compares the single retailer and multiple retailer scenarios to ascertain their effect on the extent of product misrepresentation in the marketplace. The findings propose an alternative mechanism: Having multiple retailers can mitigate strategic misrepresentation of product quality. This is due to a market correcting effect of partnering with multiple downstream players: consumers' ability to compare quality signals from multiple retailers helps them to update beliefs about the true quality of a product. For a high quality manufacturer, increasing the credibility of the quality signals eliminates part of the informational inefficiencies present in credence goods markets. This, in return, may help channel members to improve their profits. Thus, contrary to lay intuition, increasing the number of retailers may, in some cases, increase the total profitability across retailers despite enhanced competition.

The extensions of a benchmark model provide some additional insights. First, we show that misrepresentation rises regardless of who gets blamed: A proportional distribution of blame of quality problems to the retailers and the manufacturer does not eliminate this outcome. Second, the assumption of credulity is relaxed to examine the impact of consumer skepticism on the incentives to misrepresent and the channel profits. One might think that if consumers can recognize and account for retailers' incentives to misrepresent a low-quality product as being a high-quality product, the extent of such misrepresentation will be reduced. However, we demonstrate that this is not always the case; in fact, the overall effect of consumer skepticism depends on how low the product quality is. Third, we allow the retailer representation of quality to be fully strategic by eliminating any unintended misrepresentation outcomes. Even though in this case the retailer openly misleads consumers, misrepresentation - surprisingly - is not fully eliminated.

Although the literature on misrepresentation dates back to the 1970s (Akerlof, 1970), to our knowledge, this is the first paper in marketing to examine the relationship between misrepresentation and channel structure using an analytical modeling framework. Misrepresentation received heightened attention following the 2008 financial crisis (e.g., Inderst and Ottaviani (2012b), Brown and Minor (2012), Inderst and Ottaviani (2013)). Inderst and Ottaviani (2012a) consider costless communication between sellers and credulous buyers in tradition with cheap-talk models (Crawford and Sobel (1982)). These authors find that refund policies can discipline an opportunistic seller. In 
Mishra et al. (1998), the information asymmetry between sellers and buyers is explicitly considered in selling environments. Using data from service managers in the automotive industry, the authors confirm that institutional differences among retail outlets change the extent to which consumers suffer from moral hazard. The study provides a comprehensive summary of factors impacting seller moral hazard including local vs. national store ownership, number of employees, seller compensation and company culture but does not focus on channel design as a factor moderating the extent of moral hazard. We contribute to these earlier studies in several ways. First, whereas most of the earlier models focus on the seller and consumer relationship, we bring attention to the potential conflict between the manufacturer's and retailer's incentives to misrepresent to consumers in a vertical channel design. Thus, our model considers manufacturers, retailers, and consumers as opposed to only a seller (manufacturer or retailer) and consumers. In our model, the manufacturer has the power to set product quality, whereas the seller has the power to shape customers' beliefs about quality. Further, in our model signals sent can have costly consequences for consumers, sellers, and manufacturers, whereas most earlier papers assume no direct cost of misrepresentation. Our study therefore extends and complements the findings of these earlier works.

Our work also contributes to the literature concerning customer satisfaction (Oliver, 1997) and customer attribution of failure (Zeithaml (1988); Folkes (1988); Tsiros et al. (2004); Johnson and Folkes (2007)). Most of the earlier works on customer satisfaction make an assumption that setting customer expectations low will always be beneficial for profits because it should lead to higher customer satisfaction (performance exceeds customer expectations). We theoretically identify situations when the opposite effect might occur: selling a high-quality product under the guise of lower quality can decrease the profits of channel members.

Further, behavioral theorists have examined failure attribution processes by consumers (Tsiros et al., 2004; Folkes et al., 1987), yet they do not consider the strategic implications of this attribution for both manufacturers and sellers. In this paper we study how the attribution of blame for product failure is distributed between the manufacturer and retailers, and how this distribution affects their strategies and profits. Similarly, there is a large body of empirical research examining the nature of redress (after the product failure occurred) that consumers may seek based on failure attributions (Smith et al., 1999; Francken, 1983). These studies mainly focus on strategies for management of post-purchase consumer dissatisfaction, but do not attempt to address the source of discontent 
based on channel relationship conflicts.

Finally, our study contributes to the B2B literature on channel design (McGuire and Staelin (1983)), and on aligning manufacturer and retailer incentives (e.g. Jeuland and Shugan (1983); Coughlan (1985); Eliashberg and Jeuland (1986); Moorthy (1988); Purohit and Staelin (1994); Lee and Staelin (1997); Kim and Staelin (1999)). Most B2B relationships - especially those between manufacturers and retailers - are based on the exchange of credence goods (Jacques (2007), Grewal and Lilien (2012)) and misrepresentation is a common reason for conflict in B2B relationships (Phillips, 1974). Three studies that are closely linked to ours are Chu and Desai (1995) and Mishra et al. (1998). In Chu and Desai (1995), authors focus on manufacturer incentives to retailers in the form of customer satisfaction assistance and consumer-satisfaction-index bonus to ensure positive customer outcomes, namely their satisfaction with the product. Similarly, Hauser et al. (1994) examines how firms can design incentive systems to improve customer satisfaction. Consistent with the spirit of these studies, we assume that consumer dissatisfaction with the product quality and the misrepresentation can have costly consequences for the channel members. Using this assumption, we examine how manufacturers can use channel design as a tool to mitigate quality misrepresentation.

The rest of the article is organized as follows. In Section ?? we review the relevant literature to situate our model. Section 2 develops the model and in Section 3 we compare a design with single and multiple retailers in a channel; we also examine issues related to consumer welfare. In Section 4 we extend our model in several directions: we consider a scenario when the upstream member offers a menu of prices, we analyze the cases when only one of the channel members is punished by the consumer for misleading, and relax some of the assumptions we make in Section 2 . Finally, we develop some managerial implications and conclude in Section 5.

\section{Model}

Consider a channel where several downstream firms are selling the product to consumers. They obtain the product from an upstream monopolist. We will call the downstream firms the "retailers", and the upstream firm the "manufacturer" and refer to the retailers with 'she' and to the manufacturer with 'he' to help the reader follow our exposition. 
The manufacturer (denoted with $M$ ) can choose to distribute the product via one or several retailers. The number of downstream channel members is the comparative statics parameter in our paper: we first present a benchmark model where there is a single retailer (denoted with $R$ ) selling a product to consumers. Within the single retailer framework, we determine the equilibrium product quality and wholesale prices chosen by the manufacturer, as well as the product representation strategies and retail prices set by the retailer. Subsequently, we consider a dual retailer distribution channel design, where manufacturer sells its product via two retailers (denoted by $R_{1}$ and $R_{2}$ respectively). We compare the manufacturer's profits and equilibrium strategies in the two channel designs, as well as the retailer's choice of quality representation strategy.

\subsection{The Manufacturer}

There are two distinct decisions that the manufacturer makes. First, the manufacturer sets the quality of the product $\left(q_{M}\right)$ by choosing from two predetermined levels of quality: high $(H)$ or low $(L)$. Second, he sets the wholesale price of the product, $w$. The difference between quality levels is that the low-quality product can fail (after the purchase) with probability $r$, while the high-quality product never fails. Additionally, the manufacturer faces higher marginal cost of production $\left(c_{H}\right)$ for a high-quality product than when he produces a low-quality product at a $\operatorname{cost} c_{L}: c_{L}<c_{H}$.

We assume that the product quality is manufacturer's private information and cannot be observed by either retailers or consumers. Further, we assume that the failure rate of a low-quality product, $r$, is common knowledge, while production costs $c_{L}$ and $c_{H}$ are unknown to retailers or consumers.

\subsection{The Retailers}

Consistent with the notion of credence goods (e.g., Emons (1997)) consumers cannot judge the quality of the product on their own. That is why there is a need for retailers in the market: not only do the retailers serve as a point of sale, but they also signal product quality to consumers. Since the true product quality is manufacturer's private information, the retailer must first examine the product to form her opinion about its quality before the retailer can signal the product quality to consumers. For example, the retailer's examination may rely on experts or on product reviews, or retailer may run tests to form an opinion about product quality. The outcome of this examination 
depends on the actual product quality, $q_{M}$, as well as on the precision of the examination technology. Let $q_{t} \in\{H, L\}$ denote the retailer's opinion about product quality formed as a result of product examination. Let $\gamma \in(0.5,1)$ represent the precision of the product examination process, where $\gamma$ is defined as follows:

$$
\gamma=P\left(q_{t}=H \mid q_{M}=H\right)=P\left(q_{t}=L \mid q_{M}=L\right),
$$

Definition (1) suggests that the retailer has imperfect ability to detect the true quality of the product, which means that with probability $(1-\gamma)$ she will believe the product is of high quality whereas the true product quality is low and vice versa. ${ }^{3}$ We assume $\gamma>0.5$ so that a retailer can use the examination technology credibly. Furthermore, we assume that $\gamma$ is common knowledge.

Upon product examination, the retailer sends a quality signal $q_{R} \in\{L, H\}$ to consumers. Retailer's signal can match or differ from her opinion on the product quality. We refer to the quality signal $q_{R}$ sent to consumers conditional on the retailer's opinion $q_{t}$, as the "representation strategy" of the retailer. There are four possible representation strategies:

(1) "Truthful" $(T)$ : send a high (low) quality signal for a product whenever retailer believes it is of high (low) quality, i.e., $q_{R}=q_{t}$;

(2) "Overselling" $(O)$ : send a high quality signal regardless of the opinion on the product quality, i.e., $q_{R}=H$ for both $q_{t}=H$ and $q_{t}=L$;

(3) "Underselling" $(U)$ : send a low quality signal regardless of the opinion on the product quality, i.e., $q_{R}=L$ for both $q_{t}=H$ and $q_{t}=L$;

(4) "Mismatching" $(M M)$ : send a high (low) quality signal for a product that retailer believes is of low (high) quality, i.e., $q_{R} \neq q_{t}$.

Following the quality signal choice, retailer sets her price $p$ to maximize the expected profit conditional on $q_{t}$ and $q_{R}$. In a dual retailer channel, the retailers examine the product quality independently and announce their retail prices to consumers simultaneously.

\footnotetext{
${ }^{3}$ In Section 4.3 we consider a special case where retailer's examination technology is perfect $(\gamma=1)$. In this case, the retailer knows the true product quality after evaluating the product. We provide insights into how this perfect information about product quality affects the retailer's incentive to misrepresent the low-quality product.
} 


\subsection{Consumers}

Consumers purchase at most one unit of the product with a goal to maximize their utility. They are heterogeneous with respect to how much utility they derive from consuming the product when they face no product failure. This valuation parameter is denoted by $v$, and we assume that $v \sim U[0,1]$. Consumers derive zero utility from a product that fails.

Due to the credence nature of the product, consumers cannot determine the true quality of a product $\left(q_{M}\right)$ on their own. In the absence of any information about production costs and wholesale price, they cannot use the retail price to infer the true product quality either. In the benchmark model we assume that consumers are credulous: they completely rely on the retailer signal to infer product quality, i.e., they believe that the retailer is always truthful and that $q_{R}=q_{t}$. In Section 4.2, we consider a scenario where some consumers are non-credulous and discount retailer's signal, considering the possibility of strategic misrepresentation.

In the absence of any information, consumers would have to assume that a product is equally likely to be of high or low quality, hence their prior belief about the probability of product failure is $\frac{r}{2}$. However, conditional on the observed signal $q_{R}$ and the precision of the retailer's examination technology $\gamma$ they update their belief about the failure probability. Let $\rho_{i}$ denote the probability of failure conditional on observed signal $q_{R}=i$ in a single retailer channel. Let $\rho_{i j}$ denote the same probability conditional on observed signals $q_{R_{1}}=i$ and $q_{R_{1}}=j$ in a dual retailer channel. Then the expected utility of a consumer from buying the product in a single retailer channel can be formally expressed as

$$
E U^{i}=E U\left(v, p \mid q_{R}=i\right)=v\left(1-\rho_{i}\right)-p, i \in\{L, H\}
$$

and that in a dual retailer channel can be expressed as

$$
E U_{k}^{i j}=E U\left(v, p_{k} \mid q_{R_{1}}=i, q_{R_{2}}=j\right)=v\left(1-\rho_{i j}\right)-p_{k}, i \in\{L, H\},
$$

where $p_{k}$ is the price charged by retailer $R_{k}$. All consumers with non negative expected utility purchase the product.

\subsection{Quality Misrepresentation and Reputation Damage}

In this framework misrepresentation is defined as the deviation of the retailer's signal $q_{R}$ from retailer's opinion on the product quality, $q_{t}$. First, a retailer may choose to oversell the product 
and send a high quality signal, $q_{R}=H$ when she believes the product quality is low, $q_{t}=L$. Such strategic misrepresentation by overselling creates a moral hazard problem between the retailer and consumers. Second, if a retailer chooses to undersell the product, she presents the product as low quality, $q_{R}=L$, despite believing it is of high quality, $q_{t}=H$. This second type of strategic misrepresentation creates a moral hazard problem between the retailer and manufacturer.

With credence goods the true product quality may remain unknown to consumers even postpurchase. We assume that whenever the consumers discover that the true product quality $q_{M}$ differs from the quality signal $q_{R}$ sent by the retailer, the retailer faces a reputation damage of $\tau>0$ because consumers cannot tell whether the retailer strategically misrepresented her opinion about the product quality or was truthful but made an error while examining the product. Since we consider a single-period game, we use this reputation damage (cost) parameter to quantify the cumulative negative future effect on retailer's profits caused by diminished reputation. For example, this damage can come from the fact that some consumers will stop buying from this retailer altogether, or will sue the retailer for misrepresentation, or will no longer completely trust the retailer's quality signal.

In our model, the only situation where consumers learn the true product quality is when the product fails post-purchase, revealing that it is of low quality, $q_{M}=L$. If the product they have purchased never fails, consumers cannot determine whether the product is of high quality or low quality and happened not to fail. Hence it is only when consumers purchase a product accompanied by a high quality signal $q_{R}=H$ and observe product failure post-purchase, the retailer experiences reputation damage $\tau$. On the other hand, if the retailer sells the product accompanied by low quality signal $q_{R}=L$ and such product fails, no reputation damage is incurred by the retailer since the revealed product quality corresponds to the retailer's signal. Thus when making her decision about whether to send a high or low quality signal to consumers, the retailer evaluates the trade-off between the expected reputation damage and the gain in profits from selling the product with a high quality signal and a higher price.

We assume that reputation damage $\tau$ is unknown to consumers but is common knowledge for manufacturer and retailers. In case of multiple retailers, they split the $\tau$ reputation damage proportional to their demand. In the benchmark model, we assume that the reputation damage is only experienced by the retailers, but in Section 4.1, we consider a scenario where the manufacturer 
also experiences reputation damage.

\subsection{Timeline of the Game}

Within each channel design - single or dual retailer channel - we solve for equilibria strategies in a backward induction fashion. The timeline of the game is as follows:

1. The manufacturer chooses the product quality, $q_{M} \in\{H, L\}$, and then determines the wholesale price $(w)$ (consecutively).

2. The retailer examines the product and forms an opinion $q_{t}$ about its quality. Conditional on this opinion, she sets the quality signal to be sent to consumers: $q_{R} \in\{H, L\}$, and then determines the retail price. In a dual retailer channel, the two retailers conduct their product examination independently and announce their signals and prices to consumers simultaneously.

3. Consumers observe the quality signal(s) from the retailer(s), update their beliefs about product failure probability conditional on the signal(s), and calculate the expected utility from consuming the product. Consumers with non-negative expected utility purchase the product.

4. Consumers consume the product and receive utility. If the true product quality is low, then with probability $r$ it fails. If the failed product was represented to consumers as a high-quality product, then retailer(s) faces a total reputation damage equal to $\tau$.

\section{Analysis}

We start our analysis with a benchmark model where the manufacturer distributes the product via a single retailer. We then proceed with the analysis of a dual retailer channel and compare the equilibrium outcomes in order to investigate the impact of the channel design on the strategy choice incentives of the upstream and downstream channel members.

\subsection{Benchmark Model: Single Retailer Channel Design}

Consider a single retailer $R$ who sells the product of a manufacturer $M$. To deliver the key messages of our paper, we will focus on the behavior of the credulous consumers with reputation damage 
incurred by the downstream member only. In Section 4 we show that the key results obtained in the benchmark model hold even when channel members share reputation costs (Section 4.1) or when consumers are non-credulous (Section 4.2).

We solve the game in a backward induction fashion, starting with the consumers' decision to purchase the product. First, consumers need to update the product failure probability. Recall that credulous consumers believe that $q_{t}=q_{R}$. Thus when consumers observe a high quality signal, their updated product failure probability is equal to

$$
\rho_{H}=P\left(\text { failure } \mid q_{R}=H\right)=r P\left(q_{M}=L \mid q_{t}=H\right)=r(1-\gamma) .
$$

By the same token, when consumers observe a low quality signal, their updated probability of product failure is calculated as

$$
\rho_{L}=P\left(\text { failure } \mid q_{R}=L\right)=r P\left(q_{M}=L \mid q_{t}=L\right)=r \gamma .
$$

Since $\gamma>0.5$, the updated beliefs about the product failure conditional on retailer's signal are

$\rho_{H}<\frac{r}{2}<\rho_{L}$, where $\frac{r}{2}$ is the consumers' prior product failure belief. Notice that the assumption of credulity does not prevent consumers from recognizing the possibility that the product accompanied by a high quality signal might fail.

Second, consumers need to compute their expected utility from product purchase. Substituting probabilities $\rho_{H}$ and $\rho_{L}$ into consumers' utility function given in Equation (2), we obtain the valuation of the marginal consumer who is indifferent between buying and not buying the product for each quality signal sent by the retailer:

$$
\begin{aligned}
& v_{H}(p)=\frac{p}{1-r(1-\gamma)} \quad \text { if } q_{R}=H, \\
& v_{L}(p)=\frac{p}{1-r \gamma} \quad \text { if } q_{R}=L .
\end{aligned}
$$

Conditional on the signal she sends, the retailer faces a demand of $\left(1-v_{H}(p)\right)$ or $\left(1-v_{L}(p)\right)$. To determine the expected profit for each quality signal $q_{R}$ the retailer can send, she considers all possible combinations of unobservable true product quality, $q_{M}$, and her opinion on it, $q_{t}$.

If the retailer's opinion about product quality is $q_{t}=H$, she knows that with probability $\gamma$ she is correct in her assessment and there is zero risk of product failure and reputation damage if she sends a high quality signal $q_{R}=H$. With the remaining probability $(1-\gamma)$, the opinion $q_{t}$ is 
incorrect, in which case a product failure can happen with probability $r$. In the latter case, the retailer's reputation will suffer if she sends a high quality signal. Conditional on the opinion $q_{t}=H$, the retailer's expected profits from setting her quality signal for the product to be $q_{R} \in\{L, H\}$ is:

$$
\pi_{R}^{q_{R} H}(p)= \begin{cases}\left(1-v_{H}(p)\right)(p-w)-(1-\gamma) r \tau, & \text { if } q_{R}=H \\ \left(1-v_{L}(p)\right)(p-w), & \text { if } q_{R}=L,\end{cases}
$$

where $(1-\gamma) r \tau$ is the expected reputation damage if the product fails following high quality signal sent by the retailer.

If the retailer's examination technology suggests that the product is of low quality $\left(q_{t}=L\right)$, then with probability $\gamma$ this opinion is correct and the product will fail with probability $r$, in which case retailer will experience a damage to her reputation if she misrepresents the product quality by setting $q_{R}=H$. If she sends a low quality signal $q_{R}=L$, she will not experience any reputation damage. Therefore, conditional on her opinion $q_{t}=L$, retailer's expected profits from setting her quality signal for the product to be $q_{R} \in\{H, L\}$ is:

$$
\pi_{R}^{q_{R} L}(p)= \begin{cases}\left(1-v_{H}(p)\right)(p-w)-\gamma r \tau & \text { if } q_{R}=H \\ \left(1-v_{L}(p)\right)(p-w) & \text { if } q_{R}=L .\end{cases}
$$

Equations (5) and (6) together allow us to derive the conditions for the retailer to follow one of the strategies outlined earlier: Being Truthful, Overselling, Underselling, and Mismatching. The following lemma lists retailer's optimal product representation strategy conditional on the value of reputation damage $\tau$.

Lemma 1. In a single retailer channel, the retailer is

(1) Overselling: always sends quality signal $q_{R}=H$ if $\tau<\tau_{L}(w) \equiv \frac{\xi(w)}{\gamma}$,

(2) Underselling: always sends quality signal $q_{R}=L$ if $\tau>\tau_{H}(w) \equiv \frac{\xi(w)}{(1-\gamma)}$, and

(3) Truthful: sends quality signal $q_{R}=q_{t}$ otherwise;

where $\xi(w) \equiv \frac{(2 \gamma-1)\left(1-r-w^{2}+r^{2} \gamma(1-\gamma)\right)}{4(1-\gamma r)(1-(1-\gamma) r)}$. Moreover, a Mismatching strategy is never optimal.

Proof. All the proofs are relegated to the Appendix. 
Lemma 1 addresses a key research question: Under what conditions will a retailer follow truthful quality representation strategy? The lemma suggests that a truthful representation will only exist if the reputation damage is medium. A low reputation damage incentivizes moral hazard as the seller is willing to take the risk of overselling and deceiving the consumer. As the reputation damage increases past $\tau_{L}(w)$, it initially disciplines the retailer to act truthfully. But as the reputation damage further increases $\left(\tau>\tau_{H}(w)\right)$, the uncertainty about the true quality of the product in combination with high possible reputation damage forces the retailer to lower its own liability by always underselling the product.

Observation 1. The thresholds $\tau_{L}(w), \tau_{H}(w)$ of reputation cost which eliminate misrepresentation decrease in $w$ (see Figure 1).

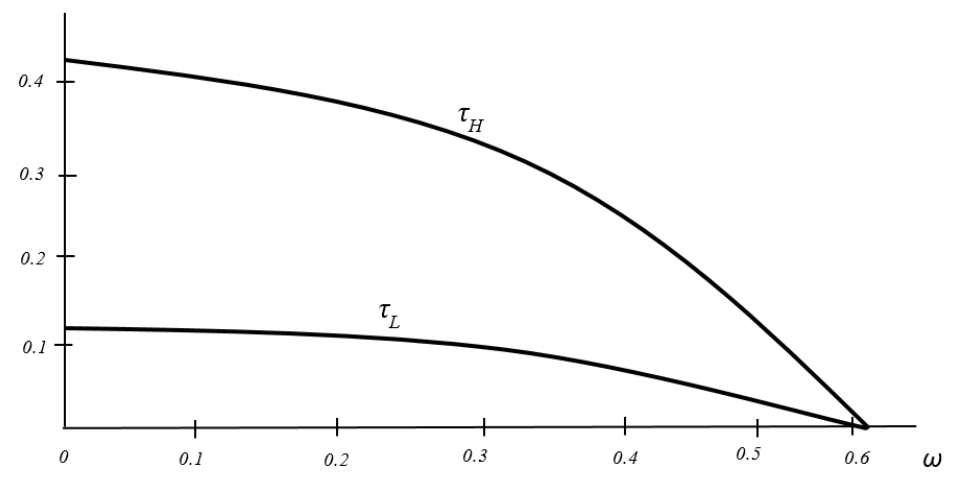

Figure 1: Thresholds $\tau_{L}, \tau_{H}$ vs. $w$ at $\gamma=0.8, r=0.7$.

An important observation pertains to the fact that the threshold values of $\tau$ which dictate the strategy of the downstream partner in a sales channel is a decreasing function of the upstream partner's price. As $w$ increases, the room for overselling and truthful strategies narrows. Specifically, when $w>\sqrt{(1-\gamma) \gamma r^{2}-r+1}$, the retailer always undersells in order to protect herself from any potential losses from reputation damage.

More importantly, the relationship between the reputation cost thresholds and $w$ show that the amount of misrepresentation in the market is, in part, determined by the manufacturer and how much leeway he gives in profits to the retailer to correct for loss from reputation damage. Stated differently, the amount of consumer deception in retail channel is determined by joint decisions of 
the upstream and downstream partners, i.e., manufactureres and retailers. To extend this insight, in Section 4.3, we analyze the case where the retailer can perfectly assess product quality $(\gamma=1)$, therefore she is fully strategic in introducing fraud in the market. In this case, the manufacturer can make choices to eliminate retailer fraud, but the analysis shows that the manufacturer still makes choices which allow products to be sold under the false premises of having higher quality than they really do.

Further, the manufacturer faces a trade-off. On the one hand, he can decrease prices slightly, through which he can encourage the retailer to better communicate the quality of its product. However, by doing so he limits his profit margins. This would imply that some products which are of high quality (and are believed to be of high quality by the sellers) are consistently presented to consumers as low-quality products, to provide an insurance for the retailer against possible reputation damage. A manufacturer with high and non-flexible prices is more likely to face a problem of motivating the retailer to communicate product quality truthfully, when everything else remains identical.

Following backward induction, we next investigate the equilibrium prices and quality set by the manufacturer in an exclusive retail channel. The derivations yield ${ }^{4}$ that the optimal wholesale prices the manufacturer charges in the pure strategy equilibrium are:

$$
\begin{aligned}
w^{H T} & =\frac{1}{2}\left(c_{H}+\frac{\beta}{(1-r+\eta)}\right) & w^{L T} & =\frac{1}{2}\left(c_{L}+\frac{\beta}{(1-\eta)}\right), \\
w^{H O} & =\frac{1}{2}\left(c_{H}+1-(1-\gamma) r\right) & w^{L O} & =\frac{1}{2}\left(c_{L}+1-(1-\gamma) r\right), \\
w^{H U} & =\frac{1}{2}\left(c_{H}+1-\gamma r\right) & w^{L U} & =\frac{1}{2}\left(c_{L}+1-\gamma r\right),
\end{aligned}
$$

where $\eta \equiv 2 r \gamma(1-\gamma)$ and $\beta \equiv 1-r+r^{2}(1-\gamma) \gamma$ and $w^{i j}$ denotes the wholesale price of product with quality $q_{M}=i \in\{L, H\}$ when retailer follows strategy $j \in\{O, T, U\}$.

Equation set (7) shows why the retailer is unable to infer manufacturer's quality from the wholesale prices: wholesale prices depend on the production cost $c_{i}, i \in\{H, L\}$ which is manufacturer's private information. Any observed value of wholesale price $w$ can be associated with multiple values of $c_{i}$. By only observing one wholesale price $w$, the retailer cannot form an opinion about product quality and must rely on the examination technology instead.

\footnotetext{
${ }^{4}$ See Proof of Lemma 2 for details.
} 
Lemma 2. In a single retailer channel, the manufacturer produces a high-quality product only if he expects the retailer to follow strategy $T$ and

$$
c_{H}<c^{T} \equiv \frac{\beta}{(1-r+\eta)}\left(1-\sqrt{\frac{1-r+\eta}{1-\eta}}\right)+c_{L} \sqrt{\frac{1-\eta}{1-r+\eta}} .
$$

Lemma 2 suggests that the provision of a high-quality product into the marketplace relies on two conditions to be met together. Not only should the cost of production be sufficiently attractive, but the manufacturer must also trust that the representation will be truthful. A low production cost alone is not sufficient for high-quality products to become available to consumers. In addition, the manufacturer must trust his channel partner to fairly communicate the quality of his product to the consumers. Lack of trust in a retail channel will result in consumers being served with low quality products.

Next, using the functions $w^{i j}$, thresholds $c^{T}$ and $\tau_{i}(w)$, we derive the equilibria strategies. ${ }^{5}$ Without loss of generality, to reduce the complexity of expressions, we set the production cost of a low-quality product to zero $\left(c_{L}=0\right)$ for the rest of the analysis. Further, we focus on the pure strategy equilibria (as depicted in Figure 2). Proposition 1 provides the conditions under which strategic misrepresentation will rise as a pure strategy equilibrium outcome in a single retailer distribution channel.

Proposition 1. In a single retailer channel,

(1) Manufacturer choosing to produce a low-quality product and retailer misrepresenting by underselling is a unique equilibrium outcome if $\tau>\tau_{H}^{L U}$;

(2) Manufacturer choosing to produce a low-quality product and retailer misrepresenting by overselling is a unique equilibrium outcome if $\tau<\tau^{L O}$ and $r<\frac{3}{5 \gamma-1} .6$

First, Proposition 1 confirms that when the manufacturer expects misrepresentation, he prefers to make a low-quality product, as Lemma 1 already hinted. Since the manufacturer bears no consequences for misrepresentation, it is never optimal for him to produce a high-quality product knowing that the retailer will misrepresent by either under or overselling, as it only involves higher

\footnotetext{
${ }^{5}$ For detailed description of equilibria, please see the Supplemental Materials, page 1.

${ }^{6}$ The closed form expressions for thresholds $\tau^{i j}$ and $\tau_{H}^{i j}$ are given in the Supplemental Materials, page 4.
} 
production cost but does not lead to any additional benefits on the demand side. In other words, there is an equilibrium level of misrepresentation in the market which is jointly determined by the retailer's and the manufacturer's preferences, as Wolinsky (1993) notes.

Further, the first part of Proposition 1 demonstrates that high reputation costs might be detrimental to the channel. When $\tau>\tau_{H}^{L U}$, the retailer is so cautious about avoiding reputation damage that even if her examination determined the quality to be high $\left(q_{t}=H\right)$, she still sends consumers a low quality signal $q_{R}=L$. The expected reputation cost, if her opinion on quality is wrong, exceeds the benefits from higher demand and profits associated with the high quality signal $\left(q_{R}=H\right)$. On the other hand, expecting the retailer to undersell the product, the manufacturer prefers to produce a low-quality product, even when the production cost $c_{H}$ is small and the high-quality product could lead to higher profits if the retailer were to represent it truthfully. As a result, consumers miss out on enjoying a high-quality product.

The second part of Proposition 1 shows that strategic misrepresentation of a low-quality product can be eliminated, regardless of the magnitude of reputation damage $\tau$, if the probability of product failure is high enough $r>\frac{3}{5 \gamma-1}$. Notice that this condition can only be satisfied for some $r \in(0,1)$ when $\gamma>0.8$; hence only when $r$ and $\gamma$ are both sufficiently high, will the expected reputation damage be high enough for the retailer to avoid misrepresenting low-quality product. In other words, if a low-quality product has a high likelihood of failure, and the retailer is known to be able to detect low quality with high precision, she will prefer not to oversell the product.

We next examine the link between strategic misrepresentation and profits. The following proposition suggests that the preferences for strategic misrepresentation versus truthful representation are not always aligned for the upstream and downstream members of the channel.

Proposition 2. In a single retailer channel,

(1) Both $(H, T)$ and $(L, O)$ are equilibrium outcomes if $c_{H}<c^{T}$ and $\tau \in\left(\tau^{H T}, \tau^{L O}\right)$. In this case, the retailer earns higher profit in $(H, T)$ outcome while the manufacturer earns higher profit in $(L, O)$ outcome:

$$
\pi_{M}^{L O^{*}}>\pi_{M}^{H T^{*}} \text { and } \pi_{R}^{L O^{*}}<\pi_{R}^{H T^{*}}
$$

(2) $(L, U)$ is the equilibrium outcome if $\tau>\tau_{H}^{L U}$. In this case, and if $c_{H}<c^{L U}$, both the retailer 


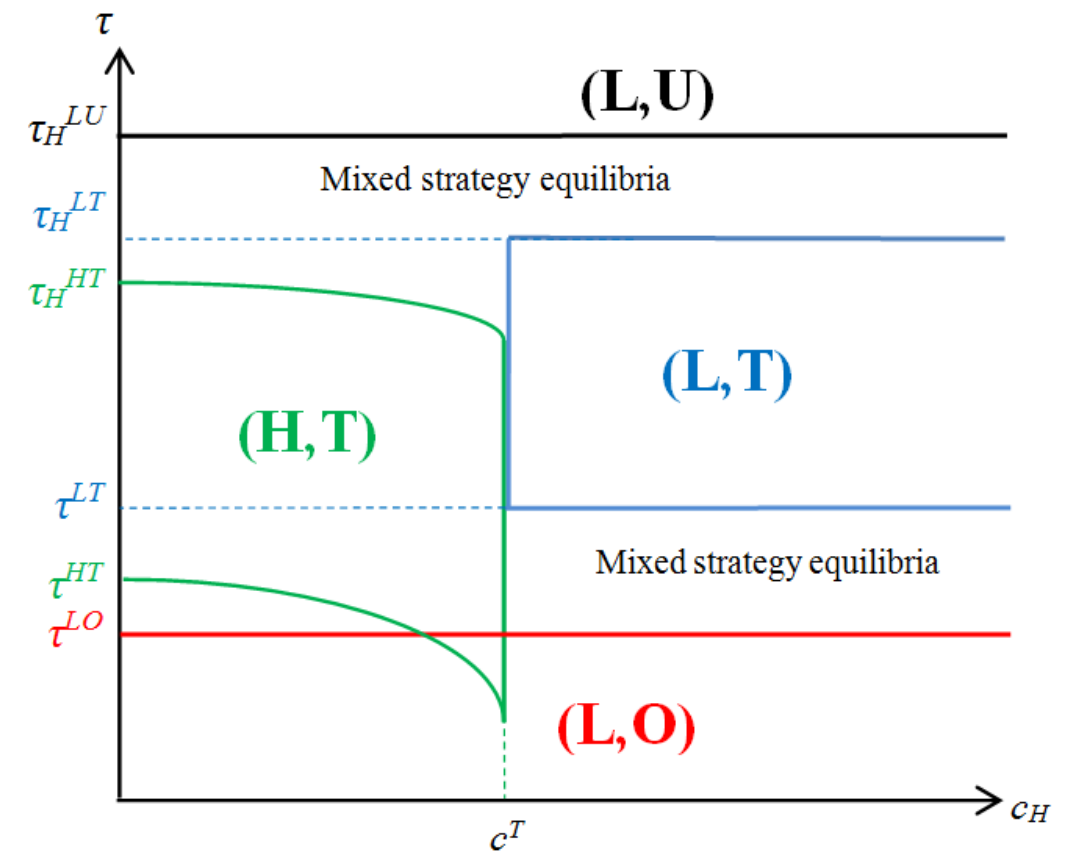

Figure 2: Pure Strategy Equilibria in $\left(\tau, c_{H}\right)$ Space, Single-Retailer Channel.

and the manufacturer face a prisoner's dilemma outcome:

$$
\pi_{k}^{L U^{*}}<\pi_{k}^{H T^{*}}, k \in\{M, R\}
$$

7 The first part of Proposition 2 demonstrates that there is a misalignment of preferences for the representation strategy used by the upstream and downstream channel members. Notice that since the manufacturer moves first, he will set product quality to low $\left(q_{M}=L\right)$, and wholesale price to $w^{L O}$, forcing the retailer to oversell the product. In this case, any dissatisfaction among consumers due to product failure can be partly blamed on the manufacturer. It can be demonstrated that aggregate consumer welfare would be higher if the manufacturer produced a high-quality product. This finding re-iterates that a manufacturer's choices play a significant role in the downstream player's decision to misrepresent the product.

The second part of Proposition 2 demonstrates that high reputation costs can be detrimental for both the manufacturer and the retailer, even though only the retailer is directly punished by consumers. When the cost of producing a high-quality product is sufficiently small, the manufacturer

\footnotetext{
${ }^{7}$ The closed-form expression for threshold $c^{L U}$ is given in the proof of Proposition 2. $\pi_{k}^{i j^{*}}$ is the profit of channel member $k \in\{M, R\}$ when the manufacturer produces a product of quality $i \in\{H, L\}$, and the retailer follows strategy $j \in\{O, T, U\} . \pi_{M}^{i j^{*}}$ is defined in proof of Lemma 2 , and $\pi_{R}^{i j^{*}}$ is defined in proof of Proposition 2.
} 
and the retailer would benefit from offering a high-quality product with truthful representation. Since the retailer's examination technology is imperfect, she cautiously chooses to set consumer expectations of quality low by underselling the product. In turn, it is not optimal for the manufacturer to produce a high-quality product, and the less preferred $(\mathrm{L}, \mathrm{U})$ outcome rises as the equilibrium.

Overall, the single-retailer analysis supports three conclusions. First, for the retailer to act truthfully, the cost of reputation should be medium. Too high and too low reputation damage incentivize the retailer to deviate from her own opinion on product quality when signalling it to consumers, i.e., to misrepresent the product to consumers. Second, producing a high-quality product requires conditions beyond profitability: the manufacturer must trust that the retailer will truthfully communicate her opinion on quality to the consumers. Third, when reputation costs are very high, consumer expectation about quality is set low by underselling. In this case, both parties (retailers and manufacturers) face a prisoner's dilemma outcome when production costs are sufficiently low: Each party earns lower profits in the $(\mathrm{L}, \mathrm{O})$ outcome due to lack of channel trust compared to an outcome of $(\mathrm{H}, \mathrm{T})$.

\subsection{Dual Retailer Channel Design}

In this section we incorporate multiple downstream partners. Specifically, the model assumes two identical retailers with similar technologies of product quality assessment; i.e., the precision of both retailers' technologies is equal to $\gamma$. We also assume that the retailers examine the quality of the product independently, and each retailer forms an independent opinion about the product quality as described by the set of equations (1). Further, upon product examination the retailers simultaneously and independently decide what quality signals to send to consumers.

With two retailers in the marketplace, consumers observe signals from both retailers and update their beliefs about the true quality of the product, and then decide whether to buy the product or not depending on their expected utility. If they decide to buy, they buy a single unit from only one of the two retailers.

Analyzing consumers' ability to observe both retailers' signals and to double check the credibility of the signal provides two main insights. First, adding a second retailer to the channel who can verify the product quality independently helps the high-quality manufacturer to convey the true 
quality of his product. If consumers observe both retailers signaling high quality, their updated probability of product failure is reduced and the expected utility from buying the product is higher than when consumers face an environment with a single retailer. Thus, both retailers can charge higher prices. Formally represented, conditional on both retailers sending high quality signals, the updated probability of product failure is smaller in a dual retailer channel:

$$
\rho_{H H}=P\left\{\text { failure } \mid q_{R_{1}}=H, q_{R_{2}}=H\right\}=\frac{(1-\gamma)^{2}}{(1-\gamma)^{2}+\gamma^{2}} r<(1-\gamma) r=\rho_{H},
$$

Similarly, conditional on both retailers sending low quality signal the product failure probability is higher with two retailers: ${ }^{8}$

$$
\rho_{L L}=P\left\{\text { failure } \mid q_{R_{1}}=L, q_{R_{2}}=L\right\}=\frac{\gamma^{2}}{(1-\gamma)^{2}+\gamma^{2}} r>\gamma r=\rho_{L} .
$$

When consumers observe conflicting retailer signals, they conclude that retailers have different opinion on the product quality: $q_{t_{1}}=L, q_{t_{2}}=H$ or $q_{t_{1}}=H, q_{t_{2}}=L$, which happens with probability $2 \gamma(1-\gamma)$. The conflicting signals are not informative to consumers because the updated probability of product failure is equal to the prior:

$$
\rho_{H L}=P\left\{\text { failure } \mid q_{R_{1}}=H, q_{R_{2}}=L\right\}=\rho_{H L}=P\left\{\text { failure } \mid q_{R_{2}}=H, q_{R_{1}}=L\right\}=\frac{r}{2} .
$$

If both retailers follow a truthful representation strategy and obtain different signals in the process of product examination, then retailer $R_{i}$ with $q_{t_{R_{i}}}=H$ would send a high quality signal to consumers $\left(q_{R_{i}}=H\right)$ and set a higher retail price, only to find no demand because consumers would choose to buy from the retailer with the lower price. Indeed, since the products sold by the two retailers are identical, consumers' expected consumption utility is the same regardless of which retailer they buy from $\left(v\left(1-\frac{r}{2}\right)\right)$, and it's only the retail price that makes the overall expected purchase utilities $E U_{1}^{i j}$ and $E U_{2}^{i j}$ different. ${ }^{9}$ Therefore in a dual retailer environment, each retailer

\footnotetext{
${ }^{8}$ Remember that consumers in our model are credulous and believe that retailers' signals are identical to their opinions, i.e., $q_{t}=q_{R}$. The total probability that two retailers independently observe the same quality signal is equal to $(1-\gamma)^{2}+\gamma^{2}$ and is obtained as follows:

$$
\begin{aligned}
& P\left(q_{t_{R_{1}}}=q_{t_{R_{2}}}\right)=P\left(q_{M}=H\right)\left[P\left(q_{t}=H \mid q_{M}=H\right)^{2}+P\left(q_{t}=L \mid q_{M}=H\right)^{2}\right]+ \\
& P\left(q_{M}=L\right)\left[P\left(q_{t}=H \mid q_{M}=L\right)^{2}+P\left(q_{t}=L \mid q_{M}=L\right)^{2}\right]=\frac{1}{2}\left(\gamma^{2}+(1-\gamma)^{2}\right)+\frac{1}{2}\left((1-\gamma)^{2}+\gamma^{2}\right)
\end{aligned}
$$

${ }^{9}$ In our model, the retailers represent a point of sale and serve an informational role by sending consumers signals
} 
may find it more attractive (as compared to single retailer case) to send a low quality signal. This way, in case of any miscoordination of signals they can avoid facing zero demand.

The expected utility $E U_{k}^{i j}$ from purchasing a product from retailer $R_{k}, k \in\{1,2\}$ when retailer $R_{1}$ sends signal $q_{R_{1}}=i$ and retailer $R_{2}$ sends signal $q_{R_{2}}=j$ is:

$$
\begin{aligned}
E U_{k}^{H H} & =\left(1-\frac{(1-\gamma)^{2}}{(1-\gamma)^{2}+\gamma^{2}} r\right) v-p_{k}, \\
E U_{k}^{L L} & =\left(1-\frac{\gamma^{2}}{(1-\gamma)^{2}+\gamma^{2}} r\right) v-p_{k}, \\
E U_{2}^{H L} & =E U_{1}^{L H}=\left(1-\frac{r}{2}\right) v-\min \left\{p_{1}, p_{2}\right\}, \\
E U_{1}^{H L} & =E U_{2}^{L H}=\left(1-\frac{r}{2}\right) v-\max \left\{p_{1}, p_{2}\right\} .
\end{aligned}
$$

Similar to the single retailer environment, we next solve for the best response functions of two retailers, identify the threshold $\tau_{L_{D}}(w)$ at which the reputation cost is high enough to enforce a truthful strategy in equilibrium, and the threshold $\tau_{H_{D}}(w)$ at which the reputation cost is high enough to enforce an underselling strategy. Throughout this section, we use the subscript $D$ to denote an outcome in a dual retailer channel. We further derive the wholesale prices (denoted $w_{D}^{i j}$, where $i=\{L, H\}, j=\{O, T, U\}$ ), and finally derive the cost threshold (denoted by $c_{D}^{T}$ ) which defines the manufacturer's choice of product quality. ${ }^{10}$

The first question is whether changing the channel design by adding more downstream retailers can provide a mechanism to reduce the extent of misrepresentation in the market. Increasing the number of retailers may suggest that the temptation to misrepresent by overselling increases because reputation damage is shared among a higher number of downstream members. However, our analysis indicates that this is not the case. A lower reputation cost tolerance is present in a dual retailer environment than in a single retailer channel: The maximum value of the overall reputation damage $\tau$ which a retailer can withstand to misrepresent a low-quality product is lower in a multiple retailer environment than in a single retailer environment. Although the retailers share reputation damage, they each are more sensitive to it, reducing their tendency to misrepresent. Proposition 3 summarizes this relationship.

about product quality. We focus on this role and thus assume that consumer utility relies on the product rather than service characteristics. This is why consumers obtain the same expected consumption utility from the product regardless of which retailer they buy from. Hence all the consumers will choose to purchase the product at the lowest price from the low quality signal retailer.

${ }^{10}$ The detailed derivations are provided in the Supplemental Materials, page 5. 
Proposition 3. $\tau_{D}^{L O}<\tau^{L O}$ : Dual retailer channel design reduces the range of reputation damage values $\tau$ where $(L, O)$ is an equilibrium outcome as compared to a single retailer environment.

Although a lower tolerance for reputation damage does not fully eliminate strategic misrepresentation by overselling in a multiple retailer channel, it decreases the retailer's tendency to send a high quality signal for a low-quality product compared to a single retailer channel. Operating with multiple retailers increases an individual retailer's risk of facing no demand in case she sends a high quality signal to the consumers. The fear of no demand provides an additional incentive for retailer $R_{i}$ to follow truthful quality representation strategy and send a low quality signal $q_{R_{i}}=L$ upon observing $q_{t_{R_{i}}}=L$. As a result, the competition between the retailers in the downstream part of the channel motivates them to not oversell the low-quality product. Thus the extent of overselling can be reduced by adding multiple distributional outlets to the downstream part of the supply chain.

Next we compare the manufacturer's incentive to produce a high-quality product in single and dual retailer environments. Proposition 4 demonstrates that the cost threshold at which the manufacturer starts producing a low-quality product is higher when operating with two retailers; in other words, the manufacturer has more leeway to produce a high-quality product. Partnering with multiple downstream partners supports provision of higher quality goods.

Proposition 4. $c_{D}^{T}>c^{T}$ : Dual retailer channel design increases the range of manufacturing cost values $c_{H}$ where $(H, T)$ is an equilibrium outcome as compared to a single retailer environment.

For any $c_{H} \in\left(c^{T}, c_{D}^{T}\right)$ and moderate values of $\tau$ (i.e., such $\tau$ that truthful strategy is optimal for the retailer in either single or dual retailer channel), the manufacturer in a single retailer channel would choose to produce a low-quality product whereas a manufacturer in a multiple retailer channel would choose to produce a high-quality product. Put differently, in a multiple retailer channel, the production of high quality products can be supported in equilibrium for higher cost margin $c_{H}$ values than those in a single retailer environment. To see the intuition, recall that operating with multiple retailers reduces the probability that a high-quality product will be mistakenly assessed as a low-quality product. If retailers are truthful, the additional high quality signal in the market leads to a higher demand because the probability of product failure is assessed (by consumers) 
to be lower. As a result, at the same production cost margin $c_{H}$ and fixed reputation damage $\tau$, operating in a multiple-retailer channel may motivate the manufacturer to choose high over low quality.

Finally, we compare the profits of the manufacturer in a single vs. dual retailer channel design. Proposition 5 addresses whether reducing misrepresentation in a dual retailer channel can drive manufacturer revenues higher.

Proposition 5. Adding a second retailer increases manufacturer's profit when he produces a highquality product and retailers follow truthful strategy, and when he produces a low-quality product and retailers misrepresent by overselling. Manufacturer's profit decreases in other outcomes:

$$
\begin{aligned}
& \pi_{M}^{H T^{*}}<\pi_{M_{D}}^{H T^{*}} \text { and } \pi_{M}^{L O^{*}}<\pi_{M_{D}}^{L O^{*}}, \\
& \pi_{M}^{L T^{*}}>\pi_{M_{D}}^{L T^{*}} \text { and } \pi_{M}^{L U^{*}}>\pi_{M_{D}}^{L U^{*}} .
\end{aligned}
$$

where the $\pi_{M}^{i j^{*}}\left(\pi_{M_{D}}^{i j^{*}}\right)$ is the optimal manufacturer's profit in a single (dual) retailer environment in the outcome $(i, j)$.

Proposition 5 allows us to reiterate a key point of our study. Compared to the single retailer design, a dual retailer design allows the manufacturer to increase his profits in both situations: if the retailer is truthful or if the retailer oversells. Importantly, if a manufacturer could trust his downstream partner to act truthfully, he would benefit from operating with multiple retailers and would obtain higher profits compared to operating with a single retailer. Following this insight, we extend our model in several directions by relaxing key assumptions.

\section{Extensions}

In this section, we relax the assumptions of the benchmark model. First, we allow the upstream member of the channel to share the reputation damage with the downstream member. Second, we relax the assumption of consumer credulity and consider the environment where consumers are skeptical about retailer's quality signal and account for the possibility of retailer misrepresenting the product quality. Finally, we analyze the environment where the retailer's examination technology is perfect $(\gamma=1)$. We will only detail the extensions in the context of a single retailer channel; notably, the direction of change is similar when there are multiple retailers. 


\subsection{Shared Reputation Damage}

In this section we relax the assumption that the reputation damage is incurred only by the downstream member of the channel. Instead, we allow consumers to punish both members: the retailer for misrepresenting and the manufacturer for offering a low-quality product. Let parameter $\lambda \in(0,1)$ quantify the proportion of blame the consumer places on the retailer. Then the manufacturer faces a reputation cost of $(1-\lambda) \tau$ and the retailer faces a cost of $\lambda \tau$.

When reputation damage is shared, the retailer's expected profits from misrepresentation by overselling strategy are as follows.

$$
\begin{aligned}
& \pi_{R_{S}}^{H L}(p)=\pi_{R_{S}}\left(q_{R}=H, p \mid q_{t}=L\right)=\left(1-v_{H}(p)\right)(p-w)-\gamma r \tau \lambda \\
& \pi_{R_{S}}^{H H}(p)=\pi_{R_{S}}\left(q_{R}=H, p \mid q_{t}=H\right)=\left(1-v_{H}(p)\right)(p-w)-(1-\gamma) r \tau \lambda
\end{aligned}
$$

where the subscript "S" denotes the outcomes in shared reputation damage scenario.

The retailer's expected profits from sending a low quality signal (under either truthful or overselling strategies) are the same as in the benchmark model (see expressions (5)-(6)) as the retailer does not incur the reputation damage when $q_{R}=L$ even if the product fails. Manufacturer's expected profits when he produces a low-quality product are also slightly different from those in the benchmark model (given by expressions (A.9)). With shared reputation damage, these profits are as follows:

$$
\begin{aligned}
& \pi_{M_{S}}^{L T}(w)=\left(w-c_{L}\right)\left(\gamma\left(1-v_{L}\left(p_{S}^{L^{*}}\right)\right)+(1-\gamma)\left(1-v_{H}\left(p_{S}^{H^{*}}\right)\right)\right)-(1-\gamma) r(1-\lambda) \tau, \\
& \pi_{M_{S}}^{L O}(w)=\left(w-c_{L}\right)\left(1-v_{H}\left(p_{S}^{H^{*}}\right)\right)-\gamma(1-\lambda) \tau r \\
& \pi_{M_{S}}^{L U}(w)=\left(w-c_{L}\right)\left(1-v_{L}\left(p_{S}^{L^{*}}\right)\right),
\end{aligned}
$$

where $\pi_{M_{S}}^{L j}(w)$ is the manufacturer's expected profit if he produces a low-quality product, sets his price to $w$, and expects the retailer to follow strategy $j \in\{O, T, U\}$.

Figure 3 maps the pure strategy equilibrium outcomes to the $(\tau, c)$ parameter space (the derivation of equilibrium outcomes is analogous to that in the benchmark model and is thus omitted), and the proposition below highlights the impact of shared reputation damage on the set of equilibrium outcomes and incentives to misrepresent in a vertical channel.

Proposition 6. When consumers attribute product failure to both the retailer and the manufacturer: 


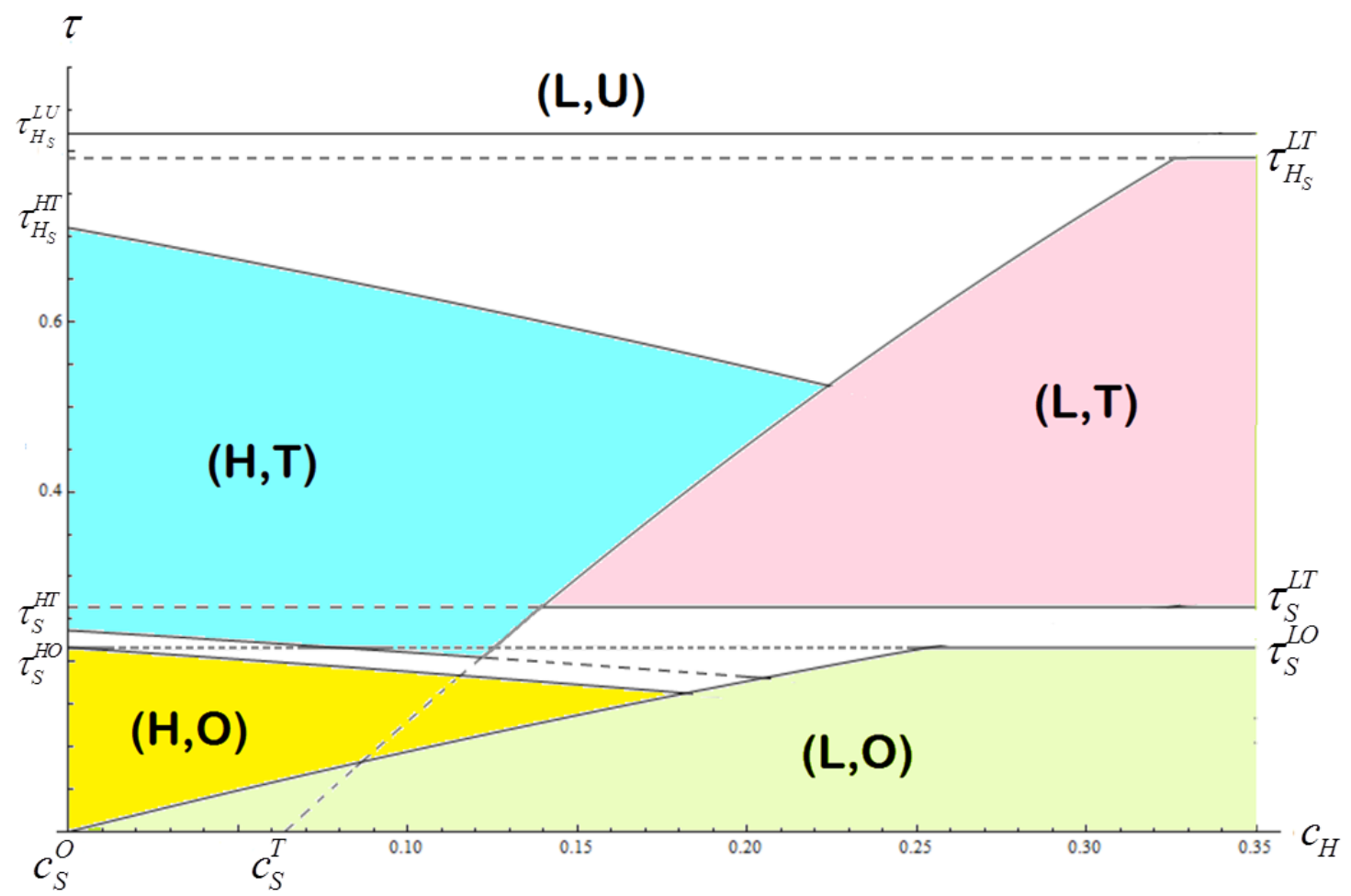

Figure 3: Pure Strategy Equilibria in $\left(\tau, c_{H}\right)$ Space, Single Retailer Channel, Shared Reputation Damage $(\gamma=.75, \lambda=.5, r=.5)$.

(1) $(H, O)$ can be an equilibrium outcome: When $c_{H}<c_{S}^{O}$, the manufacturer produces a highquality product even when he expects the retailer to misrepresent by overselling;

(2) $\tau_{H}^{L U}<\tau_{H_{S}}^{L U}$ : the range of reputation cost $\tau$ where prisoner's dilemma outcome $(L, U)$ rises is narrower compared to when only the retailer faces the reputation damage.

The first part of Proposition 6 demonstrates that sharing the reputation damage leads to the additional equilibrium outcome ( $\mathrm{H}, \mathrm{O})$, compared to the retailer shouldering all of the blame. This outcome is notably counter-intuitive. Even though the retailer follows an overselling strategy, the manufacturer still produces a high-quality product. Thus, effectively the true product quality is not misrepresented to consumers. Instead, the overselling strategy adopted by the retailer leads to "signal correction" if the retailer incorrectly evaluates the product quality to be low $\left(q_{t}=L\right)$. Neither the retailer nor the manufacturer would experience any reputation damage post-factum since a high-quality product never fails.

Observation 2. $\pi_{M_{S}}^{H O}>\pi_{M_{S}}^{H T}$. 
The observation implies that whenever outcome $(\mathrm{H}, \mathrm{T})$ is the equilibrium, it is detrimental to the manufacturer's profits. In outcome $(\mathrm{H}, \mathrm{T})$ a high-quality product can, with probability $(1-\gamma)$, be sold as a low-quality one due to the imperfection of the retailer's examination technology, leading to a lower demand. In (H,O) outcome not only is the product guaranteed to be sold as a high-quality one (even if the retailer mistakenly thinks it is of low quality upon the product examination), but the manufacturer also adds a "misrepresentation premium" to the wholesale price: $w_{S}^{H O} \geqslant w_{S}^{H T}$. Jointly, these factors lead to higher profits under the outcome $(\mathrm{H}, \mathrm{O})$.

The rate at which the consumer attributes product failure to the retailer or the manufacturer also impacts product quality. The more likely consumers are to attribute product failure to the manufacturer (higher $(1-\lambda)$ ), the more inclined the manufacturer will be to produce a high-quality product, as noted in Observation 3.

Observation 3. When the retailer follows the overselling strategy, the threshold $c_{S}^{O}$ at which the manufacturer prefers to offer a high-quality product over a low quality one is increasing with his share of reputation cost, $(1-\lambda)$.

Further, the second part of Proposition 6 shows that the prisoner's dilemma outcome $(\mathrm{L}, \mathrm{U})$ is not eliminated when consumers (partially) blame the manufacturer for misrepresentation, however, the range where this outcome rises is smaller. Remember that the $(\mathrm{L}, \mathrm{U})$ outcome is caused by the retailer being cautious in the presence of high $\tau$ : the expected damage is not worth the high demand and profit to be obtained from a high quality signal $q_{R}=H$ even when retailer believes, upon product examination, that the product has high-quality $\left(q_{t}=H\right)$. When the reputation cost is shared, the reputation cost faced by the retailer $(\lambda \tau)$ is smaller than the cost borne under full attribution. Hence for $\tau \in\left(\tau_{H}^{L U}, \tau_{H_{S}}^{L U}\right)$, underselling strategy is replaced by truthful behavior. Put simply, if the consumers can punish both channel members, the prisoner's dilemma outcome can be partially avoided.

\subsection{Skeptical Consumers}

Next, we relax the benchmark model's assumption that consumers are credulous, i.e., they believe that the signal $\left(q_{R}\right)$ sent by a retailer truthfully represents the retailer's assessment $\left(q_{R}=q_{t}\right)$. Instead, we consider consumers to be skeptical. Let consumers consider the possibility that the retailer may misrepresent a low-quality product. Specifically, we assume they believe there is only a 
chance $\phi$ that the retailer will truthfully convey the product's low quality to them. ${ }^{11}$ More formally, they believe that

$$
\phi=\operatorname{Prob}\left(q_{R}=L \mid q_{t}=L\right)
$$

Stated differently, $\phi$ represents the degree of trustworthiness of the retailer for the consumer. Since consumers are unaware of the reputation damage $\tau$, they do not see why the retailer would misrepresent a high product quality as low. As such, consumers believe if the retailer's opinion of the product quality is high $\left(q_{t}=H\right)$ then she will definitely send a high quality signal. In other words, we assume that consumers believe $P\left(q_{R}=H \mid q_{t}=H\right)=1$.

To isolate the effect of consumer skepticism, we keep the rest of our assumptions identical to the benchmark model: we consider a single retailer channel where the cost of reputation damage is incurred only by the retailer. Hereinafter the subscript ' $s c$ ' denotes the outcomes with skeptical consumers.

When consumers observe $q_{R}=H$ or $q_{R}=L$, they update the probability of product failure $\rho_{H_{s c}}$ and $\rho_{L_{s c}}$ respectively. Taking the degree of trustworthiness, $\phi$, into account and using the Bayes rule, the updated probabilities can be computed as follows:

$$
\begin{aligned}
& P\left(q_{R}=H\right)=\frac{1}{2}((1-\phi) \gamma+(1-\gamma))+\frac{1}{2}(\gamma+(1-\phi)(1-\gamma))=1-\frac{\phi}{2} \\
& P\left(q_{R}=L\right)=\frac{1}{2}(\phi \gamma)+\frac{1}{2}(\phi(1-\gamma))=\frac{\phi}{2}
\end{aligned}
$$

and hence

$$
\begin{aligned}
& \rho_{H_{s c}}=r P\left(q_{M}=L \mid q_{R}=H\right)=r \frac{P\left(q_{M}=L\right) P\left(q_{R}=H \mid q_{M}=L\right)}{P\left(q_{R}=H\right)}=r \frac{1-\phi \gamma}{2-\phi} \\
& \rho_{L_{s c}}=r P\left(q_{M}=L \mid q_{R}=L\right)=r \frac{P\left(q_{M}=L\right) P\left(q_{R}=L \mid q_{M}=L\right)}{P\left(q_{R}=L\right)}=r \gamma
\end{aligned}
$$

Note, if consumers believe that the retailer is completely trustworthy, i.e., if $\phi=1$, then these failure probabilities converge to the ones in our benchmark model with credulous consumers. Given the probabilities in Equation (11), the valuation of the consumer indifferent between buying and not

\footnotetext{
${ }^{11}$ Note, that this is not a rational expectation as we still focus on the outcomes where the retailer follows pure (as opposed to mixed) strategy.
} 
buying the product for each quality signal sent by the retailer is as follows:

$$
\begin{aligned}
v_{L_{s c}}(p) & =\frac{p}{1-\gamma r}, \text { if } q_{R}=L ; \\
v_{H_{s c}}(p) & =\frac{p(2-\phi)}{2-r(1-\gamma \phi)-\phi}, \text { if } q_{R}=H .
\end{aligned}
$$

Proposition 7 highlights the impact of consumer skepticism on the set of equilibrium outcomes and incentives to misrepresent in the channel. Since, the process of deriving equilibrium outcomes is analogous to the benchmark model, it is omitted for brevity.

Proposition 7. Compared to the environment with credulous consumers, when consumers are skeptical

(1) $\tau_{s c}^{L O}<\tau^{L O} \Longleftrightarrow\left(r<\frac{3(2-\phi)}{-5 \gamma \phi+12 \gamma+\phi-3}\right.$ and $\left.\gamma>\frac{3-\phi}{12-5 \phi}\right)$ : only if the failure probability $(r)$ is sufficiently small and examination technology $(\gamma)$ is sufficiently precise, the range of reputation cost $(\tau)$ where overselling $(L, O)$ is an equilibrium outcome becomes smaller.

(2) $\tau_{H_{s c}}^{L U}<\tau_{H}^{L U}$ : the range of reputation cost values $(\tau)$ where $(L, U)$ is the equilibrium outcome is always larger.

Contrary to lay intuition, consumer skepticism does not always decrease the retailer's incentive to misrepresent by overselling. If the product has a low failure probability, one can observe the positive effect of consumer skepticism by a decrease in the set of parameter values that support the $(L, O)$ outcome. Surprisingly, the incentive to oversell a low-quality product increases compared to the case of credulous consumers when the product is highly likely to fail. Further, the proposition indicates that consumer skepticism also has an adverse effect: the outcome $(L, U)$ where the manufacturer produces a low-quality product (even when the production cost is low enough to offer a high-quality product) rises for a broader set of parameter values.

Notice that the deleterious impact of consumer skepticism outweighs the positive effect, when the impact on the $\tau$ parameter is considered. $\left(\tau_{H_{s c}}^{L U}-\tau_{H}^{L U}\right)>\left(\tau^{L O}-\tau_{s c}^{L O}\right)$, which implies that the increase in the parameter range that supports underselling strategy in equilibrium is larger than the decrease in parameter space that supports low-quality product misrepresentation outcome (L,O). 


\subsection{Perfect Product examination Technology}

A particularly relevant question for legal cases on misrepresentation is whether a seller knowingly misrepresented a product. The benchmark model allows the retailer to represent the true product quality $q_{M}$ truthfully even when she follows misrepresentation by overselling strategy. Indeed, under such a strategy the retailer sends a high quality signal to consumers $\left(q_{R}=H\right)$ upon forming a belief $q_{t}=L$ about the product quality. In this caase here is still a $(1-\gamma)$ chance that her opinion is wrong, and the true product quality is in fact high $\left(q_{M}=H\right)$. As a result the retailer can argue that the misrepresentation was innocent. Misrepresentation, independent of the retailer's awareness of quality defects, is a reason for legal action. However, fraudulent or intentional misrepresentation have more significant legal consequences.

Now, consider a special case of the benchmark model where the retailer's examination technology is perfect. A perfect technology enables the retailer to be fully strategic in her behaviors as it removes any possibility of misrepresentation due to incorrect examination of product quality. The question we address here is whether quality misrepresentation still occurs. The following proposition summarizes the impact of retailer's certainty about product quality (the derivation of equilibrium outcomes is analogous to the benchmark model and thus is omitted).

Proposition 8. In a single retailer channel when $\gamma=1$ :

(1) An underselling strategy is never optimal for the retailer, hence the outcome $(L, U)$ never occurs in equilibrium;

(2) An overselling strategy is optimal for the retailer if reputation damage, $\tau$, and the product failure probability, $r$, are sufficiently small: $(L, O)$ is the equilibrium outcome when $\tau<$ $\frac{1}{16}\left(4-\frac{1}{1-r}\right)$, and $r<3 / 4$.

Proposition 8 demonstrates that the retailer's ability to detect true product quality only eliminates underselling. This result is intuitive: with perfect technology, the retailer knows that a high quality signal never indicates a low-quality product, therefore, underselling is never necessary. Moral hazard, however, is still present as $(\mathrm{L}, \mathrm{O})$ is the equilibrium outcome for some parameter values, although the parametric region where misrepresentation by overselling takes place is smaller. 
Indeed, one can easily see that $\tau^{L O}>\frac{1}{16}\left(4-\frac{1}{1-r}\right)$. So when the retailer is fully capable of detecting low quality, she still will not fully refrain from misrepresentation, even though all agents in the market are aware of her perfect technology.

\section{Conclusion}

In this paper, we investigate the impact of channel design on the manufacturer's and retailer's incentives to misrepresent a credence product offered in a vertical channel. Further, this is the first paper to relate product failure attribution by customers to the structure of the distribution channel. We consider a two-level channel where consumers' uncertainty about product quality is a function of the channel design. We compare two designs: a single-retailer and a dual-retailer design. Without observing any seller signals, consumers assume that the product has $\frac{r}{2}$ chance of failure. To update their beliefs, they interpret and rely on quality signals from the retailers. With each additional retailer signal, their belief about the true quality of a product is updated.

It is well known that information asymmetries present in credence goods markets lead to inefficiencies (Dulleck et al., 2011). Our study offers some novel and useful insights to managers about channel relationships and misrepresentation of credence goods in exclusive and dual-retailer channels. First, the single retailer channel analysis suggests that both low and high reputation costs give incentive to the retailer to refrain from truthfully representing the quality of a product. Moreover, the manufacturer needs to trust the retailer to act truthfully in representing product quality to offer a high quality product. When the manufacturer expects the retailer to deviate from truthful behavior, he prefers to offer a low quality product to consumers. By doing so, the manufacturer benefits from misrepresentation as well. Since their point of contact is the retailer, consumers in the main model punish the retailer, which results in the manufacturer to occasionally prefer product misrepresentation. In particular, with medium reputation cost and low cost of producing a high-quality product, the manufacturer earns higher revenue when the retailer oversells. Equally important, the manufacturer's pricing decision partly determines whether the downstream partner will misrepresent or not. A high quality manufacturer may find it beneficial to lower its price in order to induce retailer communication with consumers that the product is of high quality.

Second, in a dual-retailer or non-exclusive distribution, we find that the extent of misrepresenta- 
tion in the marketplace is reduced. This finding is counter-intuitive to the the idea that an exclusive distribution arrangement between the B2B partners can reduce moral hazard. Two forces lower misrepresentation in a non-exclusive retail channel. Primarily, with each additional downstream member in a channel, a high quality manufacturer can signal its quality more credibly. This effect partially erases the manufacturer's desire for misrepresentation of his product. Secondarily, the enhanced cost tolerance for producing a high quality good incentivizes the retailers to be truthful. Moreover, having multiple downstream members can also increase the profit of the retailers and the manufacturer, despite enhanced competition.

The outcomes we observe about the quality choices of the manufacturer and channel design may provide an explanation for why different firms operate with different distribution strategies. Aside from the reasons cited in the literature, our findings suggest that the ability to create (or, sometimes prevent) consumer misconceptions about product quality can be an important determinant of channel design. A manufacturer who prefers to sign an exclusive distribution contract with a retailer may be more likely to face misrepresentation than another who sells through multiple retailers. For example, rather than selling through a single authorized dealer, some brands may prefer to have a (small) number of authorized retailers in each market. Firms wanting to reduce the extent of misrepresentation may want their products to be sold by multiple retailers, as opposed to a single retailer. Another strategic insight that discredits lay intuition is that retailers do not have to face lower demand (and profitability) in the multiple-retailer scenario, compared to a single-retailer scenario.

We extended our model in several directions in Section 4. We relax the assumptions about consumers fully trusting the retailer signals, we allow the retailers to be fully strategic in choosing their representation and we also let consumers punish both the retailer and the manufacturer. Additional avenues that can be explored are many. Our paper studies a stylized model with single or dual retailers and a single manufacturer. Future research may find value in exploring additional channel designs, specifically when the downstream member has a stronger role. For example, for some channels, the downstream member (retailer) may be able to choose the number of manufacturers from whom to purchase. Our study can provide a benchmark for channel members considering alternate designs. We assume in the model that the retailers' role in the market is to sell goods, to signal quality, and to drive demand. Clearly, there are markets in which retailers can 
provide other functions, such as providing installation and after-sales service, thus adding to the consumers' utility. This is typically true for business-to-business and industrial markets. When the service provided yields a fixed utility to the consumer, then this fixed utility can be captured in the current model and the qualitative message of our model would not change. However, investigating the case when consumers have differential level of utilities for different services can be an interesting area of future research.

\section{References}

Akerlof, G. A. (1970). The market for" lemons": Quality uncertainty and the market mechanism. The Quarterly Journal of Economics 84(3), 488-500.

Brown, J. and D. B. Minor (2012, December). Misconduct in credence good markets. Working Paper 18608, National Bureau of Economic Research.

Chu, W. and P. Desai (1995). Channel coordination mechanisms for customer satisfaction. Marketing Science 14(4), 343-359.

Coughlan, A. T. (1985). Competition and cooperation in marketing channel choice: Theory and application. Marketing Science 4(2), 110-129.

Crawford, V. P. and J. Sobel (1982). Strategic information transmission. Econometrica 50(6), $1431-51$.

Darby, M. R. and E. Karni (1973). Free competition and the optimal amount of fraud. Journal of Law and Economics, 67-88.

Dulleck, U. and R. Kerschbamer (2006). On doctors, mechanics, and computer specialists: The economics of credence goods. Journal of Economic Literature 44(1), 5-42.

Dulleck, U., R. Kerschbamer, and M. Sutter (2011). The economics of credence goods: An experiment on the role of liability, verifiability, reputation, and competition. American Economic Review $101(2), 526-55$.

Eliashberg, J. and A. P. Jeuland (1986). The impact of competitive entry in a developing market upon dynamic pricing strategies. Marketing Science 5(1), 20-36. 
Emons, W. (1997). Credence goods and fraudelent experts. RAND Journal of Economics 28(1), $107-119$.

Folkes, V. S. (1988). Recent attribution research in consumer behavior: A review and new directions. Journal of Consumer Research 14(4), 548-565.

Folkes, V. S., S. Koletsky, and J. L. Graham (1987). A field study of causal inferences and consumer reaction: The view from the airport. Journal of Consumer Research 13(4), 534-539.

Francken, D. A. (1983). Postpurchase consumer evaluations, complaint actions and repurchase behavior. Journal of Economic Psychology 4(3), 273-290.

Grewal, R. and G. L. Lilien (2012). Business-to-business marketing: Looking back, Looking Forward. Northampton, MA: Edward Elgar Publishing.

Hauser, J. R., D. I. Simester, and B. Wernerfelt (1994). Customer satisfaction incentives. Marketing Science 13(4), 327-350.

Inderst, R. and M. Ottaviani (2012a). Financial advice. Journal of Economic Literature 50(2), $494-512$.

Inderst, R. and M. Ottaviani (2012b). How (not) to pay for advice: A framework for consumer financial protection. Journal of Financial Economics 105(2), 393-411.

Inderst, R. and M. Ottaviani (2013). Sales talk, cancellation terms and the role of consumer protection. The Review of Economic Studies 80(3), 1002-1026.

Jacques, F. M. (2007). Even commodities have customers. Harvard Business Review 85(5), 110119.

Jeuland, A. P. and S. M. Shugan (1983). Managing channel profits. Marketing Science 2(3), $239-272$.

Johnson, A. R. and V. S. Folkes (2007). How consumers' assessments of the difficulty of manufacturing a product influence quality perceptions. Journal of the Academy of Marketing Science 35(3), $317-328$. 
Kartik, N., M. Ottaviani, and F. Squintani (2007). Credulity, lies, and costly talk. Journal of Economic Theory 134(1), 93-116.

Kim, S. Y. and R. Staelin (1999). Manufacturer allowances and retailer pass-through rates in a competitive environment. Marketing Science 18(1), 59-76.

Lee, E. and R. Staelin (1997). Vertical strategic interaction: Implications for channel pricing strategy. Marketing Science 16(3), 185-207.

Martinez, K. (2009, January 21). Olive oil - who's cheatin' who? Ezine Articles.

McGuire, T. W. and R. Staelin (1983). An industry equilibrium analysis of downstream vertical integration. Marketing Science 2(2), 161-191.

Minder, R. (2012, accessed Nov 29 2014, November 23). Watchmakers move toward single-brand stores. The New York Times.

Mishra, D. P., J. B. Heide, and S. G. Cort (1998). Information asymmetry and levels of agency relationships. Journal of Marketing Research 35(3), 277-295.

Moorthy, K. S. (1988). Strategic decentralization in channels. Marketing Science 7(4), 335-355.

NHCAA (2014, accessed Nov 29 2014). The challange of healthcare fraud. NHCAA.org.

Oliver, R. L. (1997). Satisfaction: A Behavioral Perspective on the Consumer. New York: McGrawHill.

Phillips, J. J. (1974). Product misrepresentation and the doctrine of causation. Hofstra Law Review 2(2), 561-604.

Purohit, D. and R. Staelin (1994). Rentals, sales, and buybacks: Managing secondary distribution channels. Journal of Marketing Research 31(3), 325-338.

Smith, A. K., R. N. Bolton, and J. Wagner (1999). A model of customer satisfaction with service encounters involving failure and recovery. Journal of Marketing Research 36(3), 356-372.

The Gourmet Retailer (2012, September 24). Whole foods sloughs off misleading product claims. 
Tsiros, M., V. Mittal, and J. William T. Ross (2004). The role of attributions in customer satisfaction: A reexamination. Journal of Consumer Research 31(2), 476-483.

Wolinsky, A. (1993). Competition in a market for informed experts' services. The RAND Journal of Economics 24(3), 380-398.

Zeithaml, V. A. (1988). Consumer perceptions of price, quality, and value: A means-end model and synthesis of evidence. Journal of Marketing 52(3), 2-22.

\section{Appendix}

\section{Proof of Lemma 1:}

If the retailer formed opinion $q_{t}=H$ upon product examination, then with probability $\gamma$ the product has high quality $\left(q_{M}=H\right)$ and with probability $(1-\gamma)$ it has low quality $\left(q_{M}=L\right)$, in which case the product fails with probability $r$ and the retailer's reputation will suffer if her signal is high $q_{R}=H$. If the retailer sends $q_{R}=H$ upon forming the opinion $q_{t}=H$, her expected profit is:

$$
\pi_{R}^{H H}(w)=\pi_{R}\left\{q_{R}=H, p \mid q_{t}=H\right\}(w)=\left(1-v_{H}(p)\right)(p-w)-(1-\gamma) r \tau .
$$

Similarly, if the retailer formed opinion $q_{t}=L$ but sends a high quality signal $q_{R}=H$, her expected profit is:

$$
\pi_{R}^{H L}(w)=\pi_{R}\left\{q_{R}=H, p \mid q_{t}=L\right\}(w)=\left(1-v_{H}(p)\right)(p-w)-\gamma r \tau .
$$

If the retailer's opinion on product quality is $q_{t}=H$ or $q_{t}=L$ and she sends consumers a low quality signal $q_{R}=L$, independent of the true product quality, she will face no reputation cost. The expected profit in this case is:

$$
\pi_{R}^{L H}(w)=\pi_{R}^{L L}(w)=\pi_{R}\left\{q_{R}=L, p \mid q_{t}=i\right\}(w)=\left(1-v_{L}(p)\right)(p-w) .
$$

Plugging the valuation of the consumer indifferent between buying and not buying derived from Equation (4) into equations (A.1)-(A.3), and solving the first order conditions w.r.t. retailer prices yield:

$$
\begin{aligned}
& p_{H}^{*}(w)=\frac{1}{2}(1-r(1-\gamma)+w) \text { if } q_{R}=H, \\
& p_{L}^{*}(w)=\frac{1}{2}(1-r \gamma+w) \text { if } q_{R}=L .
\end{aligned}
$$


The retailer profits given in (A.1)-(A.3) can be compared after plugging the expressions obtained in (A.4):

$$
\begin{aligned}
& \pi_{R}^{H H}(w)-\pi_{R}^{L H}(w)=\frac{(1-w-(1-\gamma) r)^{2}}{4(1-(1-\gamma) r)}-\frac{(1-\gamma r-w)^{2}}{4(1-\gamma r)}-r \tau(1-\gamma), \\
& \pi_{R}^{H L}(w)-\pi_{R}^{L L}(w)=\frac{(1-w-(1-\gamma) r)^{2}}{4(1-(1-\gamma r))}-\frac{(1-w-\gamma r)^{2}}{4(1-\gamma r)}-\gamma r \tau .
\end{aligned}
$$

Expressions given in (A.5) show that depending on how large the reputation $\operatorname{cost} \tau$ is, the retailer can follow one of the three following strategies:

1. Overselling: If $\tau \in\left(0, \tau_{L}(w)\right)$ then $\pi_{R}^{H L}(w)>\pi_{R}^{L L}(w)$ and $\pi_{R}^{H H}(w)>\pi_{R}^{L H}(w)$, hence the retailer earns highest profit by setting $q_{R}=H$ regardless of observed $q_{t}$;

2. Truthful: If $\tau \in\left(\tau_{L}(w), \tau_{H}(w)\right)$ then $\pi_{R}^{H L}(w)<\pi_{R}^{L L}(w)$ and $\pi_{R}^{H H}(w)>\pi_{R}^{L H}(w)$, hence the retailer earns highest profit by setting $q_{R}=q_{t}$;

3. Underselling: If $\tau \in\left(\tau_{H}(w), \infty\right)$ then $\pi_{R}^{H L}(w)<\pi_{R}^{L L}(w)$ and $\pi_{R}^{H H}(w)<\pi_{R}^{L H}(w)$, hence the retailer earns highest profit by setting $q_{R}=L$ regardless of observed $q_{t}$,

where

$$
\begin{gathered}
\tau_{L}(w)=\frac{(2 \gamma-1)\left(1+(1-\gamma) \gamma r^{2}-r-w^{2}\right)}{4 \gamma(1-(1-\gamma) r)(1-\gamma r)}, \\
\tau_{H}(w)=\frac{(2 \gamma-1)\left(1+(1-\gamma) \gamma r^{2}-r-w^{2}\right)}{4(1-\gamma)(1-(1-\gamma) r)(1-\gamma r)} .
\end{gathered}
$$

Notice that for the Mismatching strategy to be optimal, the following two inequalities must hold simultaneously:

$$
\begin{gathered}
\pi_{R}^{H H}(w)<\pi_{R}^{L H}(w) \Leftrightarrow \tau<\tau_{L}(w), \\
\pi_{R}^{H L}(w)>\pi_{R}^{L L}(w) \Leftrightarrow \tau>\tau_{H}(w) .
\end{gathered}
$$

However, $\tau_{L}(w)<\tau_{H}(w)$ because $\gamma>1 / 2$ and inequalities (A.7) and (A.8) cannot hold together. Hence a Mismatching strategy is never optimal for the retailer.

\section{Proof of Lemma 2:}

The manufacturer can offer a high or a low-quality product. If he offers a high-quality product, there is a $(1-\gamma)$ chance that the retailer will incorrectly identify the product quality and decide that 
the quality is low. In this case she will send a low quality signal if she follows a truthful strategy and a high quality signal if she follows an overselling strategy. If the manufacturer produces a low-quality product, the retailer may incorrectly identify it as a high-quality product and match it with high quality signal when she follows a truthful strategy. The manufacturer's expected profit $\pi_{M}^{i j}$ when quality is set $q_{M}=i \in\{L, H\}$ and the retailer is following strategy $j \in\{O, T, U\}$ can be expressed formally as:

$$
\begin{aligned}
& \pi_{M}^{H T}(w)=\left(w-c_{H}\right)\left(\gamma\left(1-v_{H}^{*}\right)+(1-\gamma)\left(1-v_{L}^{*}\right)\right) \\
& \pi_{M}^{L T}(w)=\left(w-c_{L}\right)\left(\gamma\left(1-v_{L}^{*}\right)+(1-\gamma)\left(1-v_{H}^{*}\right)\right) \\
& \pi_{M}^{H O}(w)=\left(1-v_{H}^{*}\right)\left(w-c_{H}\right) \\
& \pi_{M}^{L O}(w)=\left(1-v_{H}^{*}\right)\left(w-c_{L}\right) \\
& \pi_{M}^{H U}(w)=\left(1-v_{L}^{*}\right)\left(w-c_{H}\right) \\
& \pi_{M}^{L U}(w)=\left(1-v_{L}^{*}\right)\left(w-c_{L}\right)
\end{aligned}
$$

where $v_{i}^{*} \equiv v_{i}\left(p_{i}^{*}(w)\right)$. Plugging the indifferent consumer valuations from Equation (4) and the retailer prices from (A.4) in (A.9), and solving the FOCs, the optimal wholesale prices are obtained:

$$
\begin{aligned}
w^{H T} & =\frac{c_{H}}{2}+\frac{(1-\gamma) \gamma r^{2}+1-r}{2\left(1-r\left(2 \gamma^{2}-2 \gamma+1\right)\right)}, \\
w^{L T} & =\frac{c_{L}}{2}+\frac{1-r+r^{2}(1-\gamma) \gamma}{2-4 \gamma r(1-\gamma)}, \\
w^{H O} & =\frac{1}{2}\left(c_{H}-(1-\gamma) r+1\right), \\
w^{L O} & =\frac{1}{2}\left(c_{L}-(1-\gamma) r+1\right), \\
w^{H U} & =\frac{1}{2}\left(c_{H}-\gamma r+1\right), \\
w^{L U} & =\frac{1}{2}\left(c_{L}-\gamma r+1\right),
\end{aligned}
$$

where $w^{i j}$ denotes the manufacturer prices when $q_{M}=i \in\{L, H\}$ and the retailer follows strategy $j \in\{O, T, U\}$.

Substituting prices (A.10) into the manufacturer profit functions (A.9) shows that $\pi_{M}^{L O^{*}}>\pi_{M}^{H O^{*}}$ and $\pi_{M}^{L U^{*}}>\pi_{M}^{H U^{*}}$ for any $(\gamma, r)$, where $\pi_{M}^{i j^{*}}$ stands for optimal manufacturer's profit in outcome $(i, j): \pi_{M}^{i j^{*}} \equiv \pi_{M}^{i j}\left(w^{i j}\right)$. So if the retailer follows strategy $(O)$ or $(U)$ then manufacturer's best response is not to produce a high-quality product. A high-quality product will only be produced if retailer follows truthful strategy $(T)$. 
In addition, solving equation $\pi_{M}^{H T^{*}}-\pi_{M}^{L T^{*}}=0$ for $c_{H}$ results in the threshold $c^{T}$.

\section{Proof of Proposition 1:}

Statement (1) directly follows from the list of pure strategy equilibria given in Supplemental Materials, on page 1. To obtain Statement (2) first notice that $\tau^{L O}$ (where closed form expression of $\tau^{L O}$ is given in Supplemental Materials, on page 4) is decreasing in $r$. Then solve $\tau^{L O}=0$ for $r$ to obtain $\tau^{L O}<0 \Leftrightarrow r>\frac{3}{5 \gamma-1}$. And $\tau^{L O}<0$ implies that there are no feasible (i.e., positive) values of $\tau$ that satisfy condition $\tau<\tau^{L O}$ for outcome (L,O) to rise in equilibrium.

\section{Proof of Proposition 2:}

(1) Statement $\pi_{M}^{L O^{*}}>\pi_{M}^{H T^{*}}$ follows from straightforward comparison of manufacturer's expected profits. To verify the second statement, the expected retailer's profits in outcomes $(\mathrm{H}, \mathrm{T})$ and $(\mathrm{L}, \mathrm{O})$ need to be defined first.

First note that due to the credence nature of the product $\left(q_{M}\right.$ being manufacturer's private information) and imperfection of retailer's examination technology $(\gamma<1)$, the retailer computes the expected profit from sending $q_{R}$ conditional on her opinion $q_{t}$ (e.g., $\pi_{R}^{q_{R} q_{t}}$ ) when making her decision about quality signal $q_{R}=i \in\{H, L\}$ to be sent, as opposed to the expected profit in a particular equilibrium outcome (i.e. $\pi_{R}^{q_{M} j}$ where $j \in\{O, T, U\}$ ). Thus the retailer's expected profit in $(\mathrm{H}, \mathrm{T})$ outcome should be computed as follows:

$\left.\pi_{R}^{H T^{*}}=\gamma\left(\left(1-v_{H}\left(p_{H}^{*}\left(w^{H T}\right)\right)\right)\left(p_{H}^{*}\left(w^{H T}\right)-w^{H T}\right)\right)\right)+(1-\gamma)\left(\left(1-v_{L}\left(p_{L}^{*}\left(w^{H T}\right)\right)\right)\left(p_{L}^{*}\left(w^{H T}\right)-w^{H T}\right)\right)$

Similarly, retailer's profit in $(\mathrm{L}, \mathrm{O})$ outcome is computed as follows

$$
\pi_{R}^{L O^{*}}=\left(\left(1-v_{H}\left(p_{H}^{*}\left(w^{L O}\right)\right)\right)\left(p_{H}^{*}\left(w^{L O}\right)-w^{L O}\right)\right)-r \tau
$$

Now, by substituting optimal wholesale prices and comparing retailer's expected profits in outcomes

$(\mathrm{H}, \mathrm{T})$ and $(\mathrm{L}, \mathrm{O})$ one can see that $\pi_{R}^{H T^{*}}>\pi_{R}^{L O^{*}}$.

(2) Solving the equation $\pi_{M}^{L U^{*}}=\pi_{M}^{H T^{*}}$ for $c_{T}$ results in the threshold

$$
c^{L U}=\frac{((1-(1-\gamma) r)(1-\gamma r))\left(1-\sqrt{\frac{1-(1-2 \gamma(1-\gamma)) r}{1-(1-\gamma) r}}\right)}{2(1-\gamma) \gamma r-r+1}
$$


such that manufacturer earns higher profit in outcome $(\mathrm{H}, \mathrm{T})$ than in outcome $(\mathrm{L}, \mathrm{U})$ whenever $c_{H}<c^{L U}$. Further, the retailer's expected profit in outcome $(\mathrm{L}, \mathrm{U})$ is defined as

$$
\pi_{R}^{L U^{*}}=\left(1-v_{L}\left(p_{L}^{*}\left(w^{L U}\right)\right)\right)\left(p_{L}^{*}\left(w^{L U}\right)-w^{L U}\right)
$$

and straightforward comparison shows that $\pi_{R}^{L U^{*}}<\pi_{R}^{H T^{*}}$ always.

\section{Proof of Proposition 3:}

The statement of the proposition, $\tau_{D}^{L O}<\tau^{L O}$ follows from direct comparison of the thresholds $\tau_{D}^{L O}$ and $\tau^{L O}$.

\section{Proof of Proposition 4:}

The statement of the proposition follows from direct comparison of the thresholds $c_{D}^{T}$ and $c^{T}$.

\section{Proof of Proposition 5:}

The statement of the proposition follows from direct comparison of manufacturer's profits.

Proof of Proposition 6: (1) To demonstrate the first statement of the proposition, we solve $\pi_{M_{S}}^{H O^{*}}=\pi_{M_{S}}^{L O^{*}}$ for $c_{H}$ to obtain threshold $c_{S}^{O}$ :

$$
c_{S}^{O}=1-r(1-\gamma)-\sqrt{(1-(1-\gamma) r)(1-r(-\gamma+8(1-\lambda) \tau+1))}
$$

(2) Second statement of the proposition follows from direct comparison of thresholds $\tau_{H}^{L U}$ and $\tau_{H_{S}}^{L U}$

\section{Proof of Proposition 7:}

(1) First statement of the proposition follows from solving $\tau_{s c}^{L O}<\tau^{L O}$ for $r$ : obtain $\tau_{s c}^{L O}<\tau^{L O} \Longleftrightarrow$ $\left(r<\frac{3(2-\phi)}{-5 \gamma \phi+12 \gamma+\phi-3}\right)$. Further, notice that $\frac{3(2-\phi)}{-5 \gamma \phi+12 \gamma+\phi-3}>0$ (and hence there is a non-empty set of $r$ satisfying the condition above) only if $\gamma>\frac{3-\phi}{12-5 \phi}$.

(2) Second statement of the proposition follows from direct comparison of $\tau_{H_{s c}}^{L U}$ and $\tau_{H}^{L U}$.

Proof of Proposition 8: The statement of the proposition follows from substituting $\gamma=1$ into $\tau^{L O}$ and $\tau_{H}^{L U}$. 


\section{SUPPLEMENTAL MATERIALS:}

\section{Derivations of Equilibrium Outcomes.}

\section{Equilibrium Outcomes in a Single Retailer Environment.}

We derive equilibrium strategies in backward induction fashion starting with retailer's choice of price and representation strategy. If the retailer formed an opinion $q_{t}=H$ upon product examination, then with probability $\gamma$ it is indeed a high-quality product $\left(q_{M}=H\right)$. However, there is still a $(1-\gamma)$ probability that $q_{M}=L$, in which case the product will fail with probability $r$, in which case retailer's reputation will suffer if she were to send a high quality signal $q_{R}=H$, since consumers cannot distinguish between a retailer intentionally misleading them or being sincerely wrong about the product quality. So if the retailer sends $q_{R}=H$ upon observing $q_{t}=H$, her expected profit $\pi_{R}^{q_{t} q_{R}}$ is:

$$
\pi_{R}^{H H}(w)=\pi_{R}\left\{q_{R}=H, p \mid q_{t}=H\right\}(w)=\left(1-v_{H}(p)\right)(p-w)-(1-\gamma) r \tau .
$$

Similarly, if the retailer formed opinion $q_{t}=L$ but sends a high quality signal $q_{R}=H$, her expected profit $\pi_{R}^{q_{t} q_{R}}$ is:

$$
\pi_{R}^{H L}(w)=\pi_{R}\left\{q_{R}=H, p \mid q_{t}=L\right\}(w)=\left(1-v_{H}(p)\right)(p-w)-\gamma r \tau .
$$

Further, if the retailer sends consumers a low quality signal $q_{R}=L$ regardless of the opinion

$q_{t}$ she formed about the product quality, her reputation will not suffer regardless of what the true product quality is. Her expected profit $\pi_{R}^{q_{t} q_{R}}$ in this case is:

$$
\pi_{R}^{L H}(w)=\pi_{R}^{L L}(w)=\pi_{R}\left\{q_{R}=L, p \mid q_{t}=i\right\}(w)=\left(1-v_{L}(p)\right)(p-w) .
$$

Plugging the location of indifferent consumers given in Equation (4) into equations (S.1)-(S.3), and solving the first order conditions yield optimal retailer prices:

$$
\begin{aligned}
p_{H}^{*}(w) & =\frac{1}{2}(1-r(1-\gamma)+w) \text { if } q_{R}=H, \\
p_{L}^{*}(w) & =\frac{1}{2}(1-r \gamma+w) \text { if } q_{R}=L .
\end{aligned}
$$

Plugging the optimal retail prices into the retailer's profits (S.1)-(S.3) and comparing them in 
order to derive product quality representation strategies yield:

$$
\begin{aligned}
& \pi_{R}^{H H}(w)-\pi_{R}^{L H}(w)=\frac{(1-w-(1-\gamma) r)^{2}}{4(1-(1-\gamma) r)}-\frac{(1-\gamma r-w)^{2}}{4(1-\gamma r)}-r \tau(1-\gamma), \\
& \pi_{R}^{H L}(w)-\pi_{R}^{L L}(w)=\frac{(1-w-(1-\gamma) r)^{2}}{4(1-(1-\gamma r))}-\frac{(1-w-\gamma r)^{2}}{4(1-\gamma r)}-\gamma r \tau .
\end{aligned}
$$

Equating the difference in profits given in (S.5) to zero and solving for $\tau$ we find that there are three possible strategies the retailer can follow:

1. Overselling: If $\tau \in\left(0, \tau_{L}(w)\right)$ then $\pi_{R}^{H L}(w)>\pi_{R}^{L L}(w)$ and $\pi_{R}^{H H}(w)>\pi_{R}^{L H}(w)$, hence the retailer earns highest profit by setting $q_{R}=H$ regardless of observed $q_{t}$;

2. Truthful: If $\tau \in\left(\tau_{L}(w), \tau_{H}(w)\right)$ then $\pi_{R}^{H L}(w)<\pi_{R}^{L L}(w)$ and $\pi_{R}^{H H}(w)>\pi_{R}^{L H}(w)$, hence the retailer earns highest profit by setting $q_{R}=q_{t}$;

3. Underselling: If $\tau \in\left(\tau_{H}(w), \infty\right)$ then $\pi_{R}^{H L}(w)<\pi_{R}^{L L}(w)$ and $\pi_{R}^{H H}(w)<\pi_{R}^{L H}(w)$, hence the retailer earns highest profit by setting $q_{R}=L$ regardless of observed $q_{t}$,

where

$$
\begin{aligned}
\tau_{L}(w) & =\frac{(2 \gamma-1)\left(1+(1-\gamma) \gamma r^{2}-r-w^{2}\right)}{4 \gamma(1-(1-\gamma) r)(1-\gamma r)}, \\
\tau_{H}(w) & =\frac{(2 \gamma-1)\left(1+(1-\gamma) \gamma r^{2}-r-w^{2}\right)}{4(1-\gamma)(1-(1-\gamma) r)(1-\gamma r)}
\end{aligned}
$$

For the Mismatching strategy to be optimal, the following two inequalities must hold simultaneously:

$$
\begin{gathered}
\pi_{R}^{H H}(w)<\pi_{R}^{L H}(w) \Leftrightarrow \tau<\tau_{L}(w), \\
\pi_{R}^{H L}(w)>\pi_{R}^{L L}(w) \Leftrightarrow \tau>\tau_{H}(w) .
\end{gathered}
$$

However, notice that $\tau_{L}(w)$ is always smaller than $\tau_{H}(w)$ because $\gamma>1 / 2$, hence inequalities (S.7) and (S.8) are mutually exclusive. Hence Mismatching strategy is never optimal for the retailer.

Further, at the beginning of the game, the manufacturer has two possible strategies: to offer high-quality or low-quality product. When the manufacturer offers a high-quality product, there is a $(1-\gamma)$ chance that the retailer will incorrectly identify the product quality, and decide that the quality is low. In this case she will send a low quality signal if she follows a truthful strategy, and high quality signal if she follows an overselling strategy. Likewise, when the manufacturer produces 
a low-quality product, the retailer might incorrectly identify it as a high-quality product and send a high quality signal even if she follows a truthful strategy.

The manufacturer's expected profit $\pi_{M}^{i j}$ from producing a product of quality $q_{M}=i \in\{L, H\}$ given that the retailer is following strategy $j \in\{O, T, U\}$ are calculated as follows:

$$
\begin{aligned}
& \pi_{M}^{H T}(w)=\left(w-c_{H}\right)\left(\gamma\left(1-v_{H}^{*}\right)+(1-\gamma)\left(1-v_{L}^{*}\right)\right) \\
& \pi_{M}^{L T}(w)=\left(w-c_{L}\right)\left(\gamma\left(1-v_{L}^{*}\right)+(1-\gamma)\left(1-v_{H}^{*}\right)\right) \\
& \pi_{M}^{H O}(w)=\left(1-v_{H}^{*}\right)\left(w-c_{H}\right) \\
& \pi_{M}^{L O}(w)=\left(1-v_{H}^{*}\right)\left(w-c_{L}\right) \\
& \pi_{M}^{H U}(w)=\left(1-v_{L}^{*}\right)\left(w-c_{H}\right) \\
& \pi_{M}^{L U}(w)=\left(1-v_{L}^{*}\right)\left(w-c_{L}\right)
\end{aligned}
$$

where $v_{i}^{*} \equiv v_{i}\left(p_{i}^{*}(w)\right)$.

Plugging in the indifferent consumer locations from Equation (4) and the retail price functions from (A.4) into the profit functions above, and then solving the FOCs with respect to wholesale prices yield:

$$
\begin{aligned}
w^{H T} & =\frac{c_{H}}{2}+\frac{(1-\gamma) \gamma r^{2}+1-r}{2\left(1-r\left(2 \gamma^{2}-2 \gamma+1\right)\right)}, \\
w^{L T} & =\frac{c_{L}}{2}+\frac{1-r+r^{2}(1-\gamma) \gamma}{2-4 \gamma r(1-\gamma)}, \\
w^{H O} & =\frac{1}{2}\left(c_{H}-(1-\gamma) r+1\right), \\
w^{L O} & =\frac{1}{2}\left(c_{L}-(1-\gamma) r+1\right), \\
w^{H U} & =\frac{1}{2}\left(c_{H}-\gamma r+1\right), \\
w^{L U} & =\frac{1}{2}\left(c_{L}-\gamma r+1\right),
\end{aligned}
$$

where $w^{i j}$ denotes the best response price function for the manufacturer when $q_{M}=i \in\{L, H\}$ to the retailer's strategy $j \in\{O, T, U\}$.

Now it is easy to see that if the manufacturer expects the retailer to follow strategy $(O)$ or $(U)$ then he would not choose to produce a high-quality product. Indeed, substituting these prices into manufacturer's profit functions given by (S.9) shows that $\pi_{M}^{L O^{*}}>\pi_{M}^{H O^{*}}$ and $\pi_{M}^{L U^{*}}>\pi_{M}^{H U^{*}}$ for any $(\gamma, r)$, where $\pi_{M}^{i j^{*}}$ stands for optimal manufacturer's profit in equilibrium outcome $(i, j)$ : 
$\pi_{M}^{i j^{*}} \equiv \pi_{M}^{i j}\left(w^{i j}\right)$. The manufacturer would only produce a high-quality product if the retailer follows strategy $(T)$ in equilibrium.

Finally, solving $\pi_{M}^{H T^{*}}=\pi_{M}^{L T^{*}}$ for $c_{H}$ results in the threshold $c^{T}$.

To finish the derivation of equilibrium outcomes, substitute wholesale prices $w^{i j}$ defined by Equations (S.10) into $\tau_{L}(w)$ and $\tau_{H}(w)$ defined by Equations (S.6) to obtain the following thresholds:

$$
\begin{aligned}
\tau^{L O} \equiv \tau_{L}\left(w^{L O}\right) & =\frac{(2 \gamma-1)\left(\gamma\left(16 \gamma^{3}-32 \gamma^{2}+17 \gamma-1\right) r^{2}+\left(16 \gamma^{2}-16 \gamma+1\right) r+3\right)}{16(1-\gamma)(1-2(1-\gamma) \gamma r)^{2}} \\
\tau^{L T} \equiv \tau_{L}\left(w^{L T}\right) & =\frac{(2 \gamma-1)((5 \gamma-4) r+3)}{16(1-\gamma)((\gamma-1) r+1)}, \\
\tau^{H T} & \equiv \tau_{L}\left(w^{H T}\right)=\frac{(2 \gamma-1)\left(-\frac{\left(c_{H}(2(1-\gamma) \gamma r-r+1)+(1-\gamma) \gamma r^{2}-r+1\right)^{2}}{4\left(-2 \gamma^{2} r+2 \gamma r-r+1\right)^{2}}+(1-\gamma) \gamma r^{2}-r+1\right)}{4(1-\gamma)((\gamma-1) r+1)(1-\gamma r)} \\
\tau_{H}^{H T} \equiv \tau_{H}\left(w^{H T}\right) & =\tau^{H T} \frac{\gamma}{(1-\gamma)}, \\
\tau_{H}^{L T} \equiv \tau_{H}\left(w^{L T}\right) & =\tau^{L T} \frac{\gamma}{(1-\gamma)}, \\
\tau_{H}^{L U} \equiv \tau_{H}\left(w^{L U}\right) & =\frac{(2 \gamma-1)\left(\gamma\left(16 \gamma^{3}-32 \gamma^{2}+17 \gamma-1\right) r^{2}+\left(16 \gamma^{2}-16 \gamma+1\right) r+3\right)}{16 \gamma(1-2(1-\gamma) \gamma r)^{2}}
\end{aligned}
$$

These thresholds determine which strategy the retailer would follow given a certain reputation $\operatorname{cost} \tau$ and wholesale price $w$. Combining them with the threshold $c^{T}$ that determines which strategy manufacturer would follow given a certain production cost $c_{H}$, one can obtain the following set of pure strategy equilibrium outcomes depicted in Figure 2:

$(\mathbf{L}, \mathbf{O})$ : Manufacturer produces a low-quality product $\left(q_{M}=L\right)$ and sells it to the retailer at the price $w^{L O}$. The retailer follows overselling strategy, i.e., sends signal $q_{R}=H$ regardless of her opinion on product quality $q_{t}$. This outcome is equilibrium if $\tau<\tau^{L O}$.

$(\mathbf{H}, \mathbf{T})$ : Manufacturer produces a high-quality product $\left(q_{M}=H\right)$ and sells it to the retailer at the price $w^{H T}$. The retailer follows truthful strategy, i.e., sends quality signal that matches her opinion about the product quality: $q_{R}=q_{t}$. This outcome is equilibrium if $\tau \in\left(\tau^{H T}, \tau_{H}^{H T}\right)$ and $c_{H}<c^{T}$.

$(\mathbf{L}, \mathbf{T})$ : Manufacturer produces a high-quality product $\left(q_{M}=H\right)$ and sells it to the retailer at the price $w^{H T}$. The retailer follows truthful strategy, i.e., sends quality signal that matches her 
opinion about the product quality: $q_{R}=q_{t}$. This outcome is equilibrium if $\tau \in\left(\tau^{L T}, \tau_{H}^{L T}\right)$ and $c_{H}>c^{T}$.

$(\mathbf{L}, \mathbf{U})$ : Manufacturer produces a low-quality product $\left(q_{M}=L\right)$ and sells it to the retailer at the price $w^{L U}$. The retailer follows underselling strategy, i.e., sends signal $q_{R}=L$ regardless of her quality opinion $q_{t}$. This outcome is equilibrium if if $\tau>\tau_{H}^{L U}$.

Notice that $\tau^{L O}<\tau^{L T}, \tau^{H T}<\tau^{L T}<\tau^{L U}$, which means the combined set of equilibria conditions listed above does not cover the full parameter space $\left(\tau, c_{H}\right)$. There is no pure strategy equilibrium for any pair $\left(\tau, c_{H}\right)$ which does not satisfy any of the equilibrium conditions listed above.

\section{Equilibrium Outcomes in a Dual Retailer Environment.}

Equating the expected utilities provided by Equation (8) to zero and solving for $v$ provides the location of consumer indifferent between buying and not buying:

$$
\begin{aligned}
& v_{H H}(p)=\frac{p}{1-r \frac{(1-\gamma)^{2}}{(1-\gamma)^{2}+\gamma^{2}}}, \text { if } q_{R_{1}}=q_{R_{2}}=H \\
& v_{L L}(p)=\frac{p}{1-r \frac{\gamma^{2}}{(1-\gamma)^{2}+\gamma^{2}}}, \text { if } q_{R_{1}}=q_{R_{2}}=L \\
& v_{H L}(p)=\frac{p}{1-\frac{r}{2}} \text {, if } q_{R_{1}}=H \text { and } q_{R_{2}}=L \text { or } q_{R_{2}}=H \text { and } q_{R_{1}}=L .
\end{aligned}
$$

We assume that the retailers are symmetrical, thus they set the same price when they send the same signal. Suppose one retailer forms opinion $q_{t}=H\left(q_{t}=L\right)$ upon product examination. The probability that the other retailer has the same opinion is $(1-\gamma)^{2}+\gamma^{2}$. The probability that the other retailer has arrived to a different opinion upon product examination is $2 \gamma(1-\gamma)$. If both retailers follow strategy $(T)^{12}$, then each retailer's expected profit, conditional on signal $q_{t}$ observed, is as follows:

$$
\begin{array}{ll}
\pi_{R_{D}}^{H T}(p)=\left(\gamma^{2}+(1-\gamma)^{2}\right) \frac{(p-w)\left(1-v_{H H}(p)\right)-(1-\gamma) r \tau}{2}+2 \gamma(1-\gamma) \times 0, & \text { if } q_{t}=H \\
\pi_{R_{D}}^{L T}(p)=\left(\gamma^{2}+(1-\gamma)^{2}\right) \frac{(p-w)\left(1-v_{L L}(p)\right)}{2}+2 \gamma(1-\gamma)(p-w)\left(1-v_{H L}^{*}\right), & \text { if } q_{t}=L .
\end{array}
$$

Notice that if the retailers have different opinion about product quality, they will send different signals to consumers when following truthful strategy. And the retailer who sends the high quality

\footnotetext{
${ }^{12}$ The retailers are symmetric, hence they follow the same strategy given the same parameter values
} 
signal would set its price high, only to find no demand because all consumers will buy from the retailer with the low price.

If retailers follow strategy $(O)$ then each retailer's expected profit conditional on opinion $q_{t}$ is

$$
\begin{array}{ll}
\pi_{R_{D}}^{L O}(p)=\frac{(p-w)\left(1-v_{H H}(p)\right)-\gamma r \tau}{2}, & \text { if } q_{t}=L \\
\pi_{R_{D}}^{H O}(p)=\frac{(p-w)\left(1-v_{H H}(p)\right)-(1-\gamma) r \tau}{2}, & \text { if } q_{t}=H
\end{array}
$$

Finally, if retailers follow strategy $(U)$ then each retailers' expected profit is

$$
\pi_{R_{D}}^{U}(p)=\frac{(p-w)\left(1-v_{L L}(p)\right)}{2} .
$$

By solving the first order conditions we obtain optimal retail prices as follows:

$$
\begin{aligned}
& p_{H_{D}}^{*}(w)=\frac{w+1}{2}-\frac{r}{4}+\frac{(2 \gamma-1) r}{4\left(2 \gamma^{2}-2 \gamma+1\right)}, \\
& p_{L_{D}}^{*}(w)=\frac{w+1}{2}-\frac{r}{4}-\frac{(2 \gamma(2-\gamma(3-2 \gamma))-1)(2-r) r}{4\left(2-8(1-\gamma)^{2} \gamma^{2}+\left(4 \gamma\left(\gamma^{3}-2 \gamma+1\right)-1\right) r\right)}, \\
& p_{U_{D}}^{*}(w)=\frac{w+1}{2}-\frac{r}{4}-\frac{(2 \gamma-1) r}{4\left(2 \gamma^{2}-2 \gamma+1\right)},
\end{aligned}
$$

where $p_{H_{D}}^{*}(w)$ and $p_{L_{D}}^{*}(w)$ are the prices retailers charge when they send a high or low quality signal to consumers respectively (under either $T$ or $O$ ) strategy. And $p_{U_{D}}^{*}(w)$ is the price they charge when they follow strategy $U$. Substituting these retail prices into the profit functions and solving for $\pi_{R_{D}}^{L U}(w)=\pi_{R_{D}}^{L T}(w)$ for $\tau$ to find $\tau_{L_{D}}(w)$, and $\pi_{R_{D}}^{U}(w)=\pi_{R_{D}}^{L T}(w)$ for $\tau$ to find $\tau_{H_{D}}(w)$, we find that the retailers:

- Follow strategy $(O)$ if $\tau<\tau_{L_{D}}(w)$;

- Follow strategy $(T)$ if $\tau \in\left(\tau_{L_{D}}(w), \tau_{H_{D}}(w)\right)$;

- Follow strategy $(U)$ if $\tau>\tau_{H_{D}}(w)$,

where

$$
\begin{aligned}
\tau_{L_{D}}(w)= & \frac{2}{\gamma r}\left(-\frac{\left(\gamma^{2}\left(r^{2}+8(r+1) w+2 r-8\right)-2 \gamma^{4}(r-2)(r+2 w-2)+2 \gamma^{3}((r-6) r-8 w+8)-4 \gamma r w+(r-2)(w-1)\right)^{2}}{8(r-2)(\gamma(\gamma(r-2)+2)-1)\left(-8(\gamma-1)^{2} \gamma^{2}+\left(4 \gamma\left(\gamma^{3}-2 \gamma+1\right)-1\right) r+2\right)}-\right. \\
& \left.\frac{\left((\gamma-1)^{2} r+(2(\gamma-1) \gamma+1)(w-1)\right)^{2}}{8(2(\gamma-1) \gamma+1)\left(-2 \gamma(\gamma-1)+(\gamma-1)^{2} r-1\right)}\right), \\
\tau_{H_{D}}(w)= & \frac{\frac{\left(\gamma^{2}(r+2 w-2)-2 \gamma(w-1)+w-1\right)^{2}}{(2(\gamma-1) \gamma+1)(\gamma(\gamma(r-2)+2)-1)}-\frac{\left((1-\gamma)^{2} r+(2(\gamma-1) \gamma+1)(w-1)\right)^{2}}{-2 \gamma(\gamma-1)+(\gamma-1)^{2} r-1}}{4 r(1-\gamma)(1-2(1-\gamma) \gamma)} .
\end{aligned}
$$


Next we consider the manufacturer's expected profits:

$$
\begin{aligned}
& \pi_{M_{D}}^{H T}(w)=\left(w-c_{H}\right)\left(\gamma^{2}\left(1-v_{H H}\left(p_{H_{D}}^{*}\right)\right)+(1-\gamma)^{2}\left(1-v_{L L}\left(p_{L_{D}}^{*}\right)\right)+2 \gamma(1-\gamma)\left(1-v_{H L}\left(p_{H_{D}}^{*}\right)\right)\right) \\
& \pi_{M_{D}}^{L T}(w)=\left(w-c_{L}\right)\left(\gamma^{2}\left(1-v_{L L}\left(p_{L_{D}}^{*}\right)\right)+(1-\gamma)^{2}\left(1-v_{H H}\left(p_{H_{D}}^{*}\right)\right)+2 \gamma(1-\gamma)\left(1-v_{H L}\left(p_{H_{D}}^{*}\right)\right)\right. \\
& \pi_{M_{D}}^{H O}(w)=\left(w-c_{H}\right)\left(1-v_{H H}\left(p_{H_{D}}^{*}\right)\right) \\
& \pi_{M_{D}}^{L O}(w)=\left(w-c_{L}\right)\left(1-v_{H H}\left(p_{H_{D}}^{*}\right)\right) \\
& \pi_{M_{D}}^{H U}(w)=\left(w-c_{H}\right)\left(1-v_{L L}\left(p_{U_{D}}^{*}\right)\right) \\
& \pi_{M_{D}}^{L U}(w)=\left(w-c_{L}\right)\left(1-v_{L L}\left(p_{U_{D}}^{*}\right)\right)
\end{aligned}
$$

where $\pi_{M_{D}}^{i j}(w)$ is manufacturer's expected profit if he produces product of quality $i \in\{H, L\}$, sets wholesale price $w$, and expects retailer to follow strategy $j \in\{O, T, U\}$.

The following wholesale prices maximize manufacturer's profit in each case: ${ }^{13}$

$w_{D}^{H T}=\frac{c_{H}}{2}+\frac{(2-r)\left(-2 \gamma(1-\gamma)+(1-\gamma)^{2}(-r)+1\right)(1-\gamma(2-\gamma(2-r)))\left(-8(1-\gamma)^{2} \gamma^{2}-(1-2(1-\gamma) \gamma(3-2(3-\gamma) \gamma)) r+2\right)}{2\left(2(1-2(1-\gamma) \gamma)^{2}+(1-2(1-\gamma) \gamma(3-5(1-\gamma) \gamma)) r^{2}-(1-2(1-\gamma) \gamma)(3-8(1-\gamma) \gamma) r\right)\left(-8(1-\gamma)^{2} \gamma^{2}-\left(1-4 \gamma\left(\gamma^{3}-2 \gamma+1\right)\right) r+2\right)}$

$w_{D}^{L T}=\frac{(2-r)\left(2 \gamma(1-\gamma)+(1-\gamma)^{2} r-1\right)(\gamma(2-\gamma(2-r))-1)\left(-8(1-\gamma)^{2} \gamma^{2}+\left(2 \gamma\left(6 \gamma^{3}-8 \gamma^{2}+\gamma+1\right)-1\right) r+2\right)}{2\left(2(2(\gamma-1) \gamma+1)^{2}+2(1-\gamma)^{2} \gamma^{2} r^{2}+(-2(\gamma-1) \gamma-1) r\right)\left(-8(1-\gamma)^{2} \gamma^{2}+\left(4 \gamma\left(\gamma^{3}-2 \gamma+1\right)-1\right) r+2\right)}$,

$w_{D}^{L O}=\frac{1}{2}-\frac{(1-\gamma)^{2} r}{2(2 \gamma(\gamma-1)+1)}$,

$w_{D}^{H O}=w_{D}^{L O}+\frac{c_{H}}{2}$,

$w_{D}^{L U}=\frac{1}{2}-\frac{\gamma^{2} r}{2(2 \gamma(\gamma-1)+1)}$,

$w_{D}^{H U}=w_{D}^{L U}+\frac{c_{H}}{2}$.

Define $\pi_{M_{D}}^{i j^{*}} \equiv \pi_{M_{D}}^{i j}\left(w^{i j}\right)$. As in the single retailer case, it is easy to see that manufacturer would not produce a high-quality product if retailer follows $(U)$ or $(O)$ strategy, because

$$
\begin{aligned}
& \pi_{M_{D}}^{H U^{*}}<\pi_{M_{D}}^{L U^{*}}, \\
& \pi_{M_{D}}^{H O *}<\pi_{M_{D}}^{L O^{*}} .
\end{aligned}
$$

Further, solve $\pi_{M_{D}}^{H T^{*}}=\pi_{M_{D}}^{L T^{*}}$ for $c_{H}$ : Equation $\pi_{M_{D}}^{H T^{*}}-\pi_{M_{D}}^{L T^{*}}=0$ is quadratic in $c_{H}$ with positive quadratic coefficient. Denote roots of this equation as $c_{1}$ and $c_{2}$ where $c_{1}<c_{2}$. It is easy to see that $c_{1}>0$ and that $\pi_{M_{D}}^{H T^{*}}$ is not feasible for $c_{H}>c_{2}$. Hence $\pi_{M_{D}}^{H T^{*}}>\pi_{M_{D}}^{L T^{*}} \Longleftrightarrow c_{H}<c_{1}$. Denote

\footnotetext{
${ }^{13}$ We continue with assumption $c_{L}=0$ as in the exclusive retailer case.
} 
$c_{D}^{T} \equiv c_{1}$. Here

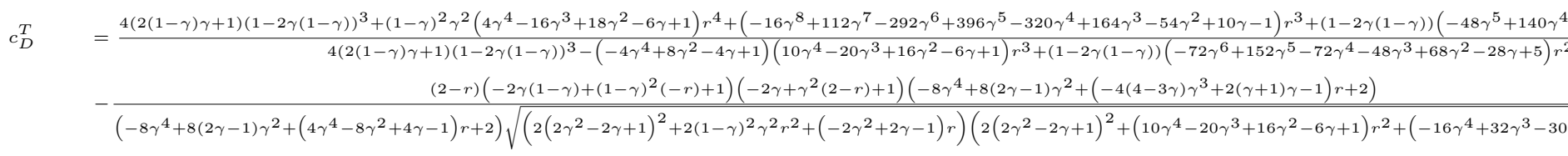

With $\tau_{L_{D}}(w), \tau_{H_{D}}(w), w_{D}^{i j}$, and $c_{D}^{T}$ defined above we can list the pure strategy equilibria in the dual-retailer channel environment:

$(\mathbf{L}, \mathbf{O})$ : Manufacturer produces a low-quality product $\left(q_{M}=L\right)$ and sells it to the retailer at the price $w_{D}^{L O}$. The retailer chooses overselling strategy, i.e. sends signal $q_{R}=H$ regardless of the received signal $q_{t}$. This outcome is equilibrium if $\tau<\tau_{D}^{L O}$.

$(\mathbf{H}, \mathbf{T})$ : Manufacturer produces a high-quality product $\left(q_{M}=H\right)$ and sells it to the retailer at the price $w_{D}^{H T}$. The retailer chooses truthful strategy, i.e. sends quality signal that matches signal she has received: $q_{R}=q_{t}$. This outcome is equilibrium if $\tau \in\left(\tau_{D}^{H T}, \tau_{H_{D}}^{H T}\right)$ and $c_{H}<c_{D}^{T}$.

$(\mathbf{L}, \mathbf{T})$ : Manufacturer produces a high-quality product $\left(q_{M}=H\right)$ and sells it to the retailer at the price $w_{D}^{H T}$. The retailer chooses truthful strategy, i.e. sends quality signal that matches signal she has received: $q_{R}=q_{t}$. This outcome is equilibrium if $\tau \in\left(\tau_{D}^{L T}, \tau_{H_{D}}^{L T}\right)$ and $c_{H}>c_{D}^{T}$.

$(\mathbf{L}, \mathbf{U})$ : Manufacturer produces a low-quality product $\left(q_{M}=L\right)$ and sells it to the retailer at the price $w_{D}^{L U}$. The retailer chooses underselling strategy, i.e. sends signal $q_{R}=L$ regardless of the received signal $q_{t}$. This outcome is equilibrium if $\tau>\tau_{H_{D}}^{L U}$.

where $\tau_{D}^{i j} \equiv \tau_{L_{D}}\left(w_{D}^{i j}\right)$ and $\tau_{H_{D}}^{i j} \equiv \tau_{H_{D}}\left(w_{D}^{i j}\right)$

\section{Equilibrium Outcomes in the Model With Shared Reputation Damage:}

The equilibrium outcomes for the case where reputation damage is shared between retailer and manufacturer are derived in backward induction fashion analogous to the benchmark model. Here are the outcomes for each of the stages:

Optimal retail prices:

$$
\begin{aligned}
p_{S}^{H}(w) & =\frac{1}{2}(1-(1-\gamma) r+w) \text { if } q_{R}=H \\
p_{S}^{L}(w) & =\frac{1}{2}(1-\gamma r+w) \text { if } q_{R}=L .
\end{aligned}
$$


Reputation cost thresholds:

$$
\begin{aligned}
\tau_{L_{S}}(w) & =\frac{(2 \gamma-1)\left((1-\gamma) \gamma r^{2}-r-w^{2}+1\right)}{4 \gamma \lambda(1-(1-\gamma) r)(1-\gamma r)} \\
\tau_{H_{S}}(w) & =\tau_{L_{S}}(w) \frac{\gamma}{1-\gamma}
\end{aligned}
$$

Optimal wholesale prices:

$$
\begin{aligned}
w_{S}^{H T} & =\frac{1}{4}\left(2 c_{H}+r\right)+\frac{r^{2}-3 r+2}{4(2(1-\gamma) \gamma r-r+1)}, \\
w_{S}^{L T} & =\frac{2-r}{4(1-2 \gamma(1-\gamma) r)}-\frac{r}{4}, \\
w_{S}^{H O} & =\frac{1}{2}\left(c_{H}-r+1\right)+\frac{\gamma r}{2}, \\
w_{S}^{L O} & =\frac{\gamma r}{2}+\frac{1-r}{2}, \\
w_{S}^{H U} & =\frac{c_{H}+1}{2}-\frac{\gamma r}{2}, \\
w_{S}^{L U} & =\frac{1}{2}-\frac{\gamma r}{2} .
\end{aligned}
$$

Manufacturer's profits in each equilibrium outcome

$$
\begin{aligned}
\pi_{M_{S}}^{H T^{*}} & =\frac{\left(1-c_{H}(2(1-\gamma) \gamma r-r)+(1-\gamma) \gamma r^{2}-r+1\right)^{2}}{8(1-(1-\gamma) r)(1-\gamma r)(2(1-\gamma) \gamma r-r+1)} \\
\pi_{M_{S}}^{L T^{*}} & =\frac{(1-\gamma) \gamma r^{2}-r+1}{8\left(2 \gamma^{2} r-2 \gamma r+1\right)}-(1-\gamma)(1-\lambda) r \tau \\
\pi_{M_{S}}^{H O^{*}} & =\frac{\left(1-c_{H}-(1-\gamma) r\right)^{2}}{8(1-(1-\gamma) r)} \\
\pi_{M_{S}}^{L O^{*}} & =\frac{1}{8}(1-(1-\gamma) r)-(1-\lambda) r \tau \\
\pi_{M_{S}}^{H U^{*}} & =\frac{\left(1-c_{H}-\gamma r\right)^{2}}{8(1-\gamma r)} \\
\pi_{M_{S}}^{L U^{*}} & =\frac{1}{8}-\frac{\gamma r}{8} .
\end{aligned}
$$

First, notice that $\pi_{M_{S}}^{L U^{*}}>\pi_{M_{S}}^{H U^{*}}$ for all feasible parameter values: i.e., it is never optimal for the manufacturer to produce high-quality product in response to retailer following underselling strategy, hence $(\mathrm{H}, \mathrm{U})$ is never an equilibrium. The other five outcomes can be equilibrium outcomes, depending on $\tau$ and $c_{H}$.

To determine thresholds in terms of $\tau$ that define retailer's choice of product quality represen- 
tation strategy $(\mathrm{O}, \mathrm{T}, \mathrm{U})$ substitute optimal wholesale prices into $\tau_{H_{S}}$ and $\tau_{L_{S}}$ :

$$
\begin{aligned}
\tau_{S}^{H O}= & \frac{(2 \gamma-1)\left(-c_{H}^{2}-2 \gamma\left(c_{H}+1\right) r-2\left(1-c_{H}\right) r-2 c_{H}-5 \gamma^{2} r^{2}+6 \gamma r^{2}-r^{2}+3\right)}{16 \gamma \lambda(1-\gamma r)(\gamma r-r+1)}, \\
\tau_{S}^{L O}= & \frac{(2 \gamma-1)(-5 \gamma r+r+3)}{16 \gamma \lambda(1-\gamma r)}, \\
\tau_{S}^{H T}= & \frac{(2 \gamma-1)\left(-\frac{\left(c_{H}\left(2 \gamma^{2} r-2 \gamma r+r-1\right)+(\gamma-1) \gamma r^{2}+r-1\right)^{2}}{4\left(2 \gamma^{2} r-2 \gamma r+r-1\right)^{2}}+(1-\gamma) \gamma r^{2}-r+1\right)}{4 \gamma \lambda(1-(1-\gamma) r)(1-\gamma r)}, \\
\tau_{H_{S}}^{H T}= & \frac{(2 \gamma-1)\left(-\frac{\left(\gamma^{2} r\left(2 c_{H}+r\right)-\gamma r\left(2 c_{H}+r\right)+\left(c_{H}+1\right)(r-1)\right)^{2}}{4((2(\gamma-1) \gamma+1) r-1)^{2}}+(1-\gamma) \gamma r^{2}-r+1\right)}{4(1-\gamma) \lambda((\gamma-1) r+1)(1-\gamma r)}, \\
\tau_{S}^{L T}= & \frac{(2 \gamma-1)\left(16 \gamma^{4} r^{2}-32 \gamma^{3} r^{2}+17 \gamma^{2} r^{2}-\gamma r^{2}+16 \gamma^{2} r-16 \gamma r+r+3\right)}{16 \gamma \lambda\left(2 \gamma^{2} r-2 \gamma r+1\right)^{2}}, \\
\tau_{H_{S}}^{L T}= & \frac{(2 \gamma-1)\left(17 \gamma^{2} r^{2}-\gamma r^{2}-16 \gamma r\left(2 \gamma^{2}-\gamma-r \gamma^{3}+1\right)+r+3\right)}{16(1-\gamma) \lambda(1-2 \gamma(1-\gamma) r)^{2}}, \\
\tau_{H_{S}}^{L U}= & \frac{(2 \gamma-1)(5 \gamma r-4 r+3)}{16(1-\gamma) \lambda(1-(1-\gamma) r)} .
\end{aligned}
$$

To determine thresholds in terms of $c_{H}$ that define manufacturer's choice of product quality $H$ or $L$, solve $\pi_{M_{S}}^{H T^{*}}=\pi_{M_{S}}^{L T^{*}}=$ for $c_{H}$ to obtain

$$
\begin{aligned}
c_{S}^{T}= & \frac{(1-\gamma) \gamma r^{2}-r+1}{2(1-\gamma) \gamma r-r+1}- \\
& \frac{\sqrt{((2 \gamma(1-\gamma)-1) r+1)\left(2(1-\gamma)^{2} \gamma^{2} r^{3}-3(1-\gamma) \gamma r^{2}+(2(1-\gamma) \gamma+1) r-1\right)\left((\gamma-1) \gamma r^{2}(16(1-\gamma)(1-\lambda) \tau+1)+r(8(1-\gamma)(1-\lambda) \tau+1)-1\right)}}{\left(2 \gamma^{2} r-2 \gamma r+1\right)(2(1-\gamma) \gamma r-r+1)}
\end{aligned}
$$

and solve $\pi_{M_{S}}^{H O^{*}}=\pi_{M_{S}}^{L O^{*}}=$ for $c_{H}$ to obtain

$$
c_{S}^{O}=1+r(1-\gamma)-\sqrt{(1-(1-\gamma) r)(1-r(-\gamma+8(1-\lambda) \tau+1))}
$$

\section{Equilibrium Outcomes in Case of Skeptical Consumers:}

The equilibrium outcomes for the case of skeptical consumers are derived in backward induction fashion analogous to the benchmark model. Here are the outcomes for each of the stages: Optimal retail prices:

$$
\begin{aligned}
p_{s c}^{H}(w) & =\frac{1+w}{2}-\frac{(1-\gamma \phi) r}{2(2-\phi)}, \\
p_{s c}^{L}(w) & =\frac{1}{2}(1-\gamma r+w) .
\end{aligned}
$$


Reputation damage thresholds:

$$
\begin{aligned}
\tau_{L_{s c}}(w) & =\frac{2 \gamma-1}{4 \gamma(2-\phi)}-\frac{(2 \gamma-1) w^{2}}{4 \gamma(1-\gamma r)(-\phi(1-\gamma r)-r+2)} \\
\tau_{H_{s c}}(w) & =\tau_{L_{s c}}(w) \frac{\gamma}{1-\gamma}
\end{aligned}
$$

Optimal wholesale prices:

$$
\begin{aligned}
w_{s c}^{H T} & =\frac{1}{2}\left(c_{H}-\gamma r+1\right)+\frac{2 \gamma^{2}(1-\gamma) r-\gamma r(1-\gamma r)}{2(-\gamma r(2 \gamma-\phi)+(1-\gamma)(-r)-\phi+2)}, \\
w_{s c}^{L T} & =\frac{\left(2 \gamma^{2}-3 \gamma+1\right) r(\gamma r-1)}{2 \gamma r(2 \gamma+\phi-3)-2 \phi+4}+\frac{1}{2}(1-\gamma r), \\
w_{s c}^{H O} & =\frac{1}{2}\left(c_{H}-\gamma r+1\right)+\frac{(2 \gamma-1) r}{2(2-\phi)}, \\
w_{s c}^{L O} & =\frac{(2 \gamma-1) r}{2(2-\phi)}+\frac{1}{2}(1-\gamma r), \\
w_{s c}^{H U} & =\frac{1}{2}\left(1+c_{H}-\gamma r\right), \\
w_{s c}^{L U} & =\frac{1}{2}(1-\gamma r) .
\end{aligned}
$$

Manufacturer's profits in each outcome

$$
\begin{aligned}
\pi_{M_{s c}}^{H T^{*}} & =\frac{\left(c_{H}(r(\gamma(-2 \gamma+\phi+1)-1)-\phi+2)+(\gamma r-1)(r(\gamma \phi-1)-\phi+2)\right)^{2}}{8(1-\gamma r)(r(\gamma \phi-1)-\phi+2)\left(-r\left(2 \gamma^{2}-\gamma(\phi+1)+1\right)-\phi+2\right)}, \\
\pi_{M_{s c}}^{L T^{*}} & =\frac{(1-\gamma r)(-r(1-\gamma \phi)-\phi+2)}{8(\gamma(-r)(-2 \gamma-\phi+3)-\phi+2)}, \\
\pi_{M_{s c}}^{H O^{*}} & =\frac{\left(\phi\left(c_{H}+\gamma r\right)+2\left(1-c_{H}\right)-r-\phi\right)^{2}}{8(2-\phi)(r(\gamma \phi-1)-\phi+2)} \\
\pi_{M_{s c}}^{L O^{*}} & =\frac{-\phi(1-\gamma r)-r+2}{8(2-\phi)}, \\
\pi_{M_{s c}}^{H U^{*}} & =\frac{\left(1-c_{H}-\gamma r\right)^{2}}{8(1-\gamma r)} \\
\pi_{M_{s c}}^{L U^{*}} & =\frac{1}{8}(1-\gamma r) .
\end{aligned}
$$

First, notice that $\pi_{M_{s c}}^{L U^{*}}>\pi_{M_{s c}}^{H U^{*}}$ and $\pi_{M_{s c}}^{L O^{*}}>\pi_{M_{s c}}^{H O^{*}}$ for all feasible parameter values: i.e., it is never optimal for the manufacturer to produce a high-quality product in response to the retailer following underselling or overselling strategy, hence neither $(\mathrm{H}, \mathrm{U})$ nor $(\mathrm{H}, \mathrm{O})$ rises in equilibrium. The other four outcomes can be equilibrium outcomes, depending on $\tau$ and $c_{H}$.

To determine thresholds in terms of $\tau$ that define retailer's choice of product quality represen- 
tation strategy $(\mathrm{O}, \mathrm{T}, \mathrm{U})$ substitute optimal wholesale prices into $\tau_{H_{S}}$ and $\tau_{L_{S}}$ :

$$
\begin{aligned}
\tau_{s c}^{L O} & =\frac{3(2 \gamma-1)}{16 \gamma(2-\phi)}-\frac{(2 \gamma-1)^{2} r}{16 \gamma(2-\phi)^{2}(1-\gamma r)}, \\
\tau_{s c}^{H T} & =\frac{(2 \gamma-1)\left(\frac{4}{2-\phi}-\frac{c_{H}^{2}}{2-\phi+(1-\gamma r)(-r(1-\gamma \phi))}-\frac{2 c_{H}}{2-\phi-r(1-\gamma(1-2 \gamma+\phi))}+\frac{(1-\gamma r)(2-\phi-r(1-\gamma \phi))}{(2-\phi-r(\gamma(2 \gamma-\phi-1)+1))^{2}}\right)}{16 \gamma}, \\
\tau_{H_{s c}}^{H T} & =\tau_{s c}^{H T} \frac{\gamma}{1-\gamma}, \\
\tau_{s c}^{L T} & =\frac{2 \gamma-1}{4 \gamma(2-\phi)}-\frac{(1-\gamma r)\left(4(2-\gamma) \gamma^{2} r-5 \gamma r+r\right)}{16 \gamma(2-\phi-r \gamma(3-2 \gamma-\phi))^{2}}-\frac{(2 \gamma-1)(1-\gamma r)}{16 \gamma(2-\phi-r \gamma(3-2 \gamma-\phi))}, \\
\tau_{H_{s c}}^{L T} & =\tau_{s c}^{L T} \frac{\gamma}{1-\gamma}, \\
\tau_{H_{s c}}^{L U} & =\frac{2 \gamma-1}{4(1-\gamma)(2-\phi)}-\frac{(2 \gamma-1)(1-\gamma r)}{16(1-\gamma)(2-r-\phi(1-\gamma r))} .
\end{aligned}
$$

To determine thresholds in terms of $c_{H}$ that define manufacturer's choice of product quality $\mathrm{H}$ or L, solve $\pi_{M_{S}}^{H T^{*}}=\pi_{M_{S}}^{L T^{*}}=$ for $c_{H}$ to obtain

$$
\begin{aligned}
c_{s c}^{T}= & \frac{2-\phi-r(1-\gamma r)(1-\gamma \phi))}{2-\phi+r(1-\gamma(1-2 \gamma+\phi))} \\
& -\frac{(1-\gamma r)(r(\gamma \phi-1)-\phi+2) \sqrt{(2-r \gamma(3-2 \gamma-\phi)-\phi)(2-\phi+r(\gamma(1-2 \gamma+\phi)-1))}}{(2-\phi-r \gamma(3-2 \gamma-\phi))(2-\phi-r(1-\gamma(1-2 \gamma+\phi)))} .
\end{aligned}
$$

